\title{
The Dorsal Raphe Regulates the Duration of Attack through the Medial Orbitofrontal Cortex and Medial Amygdala
}

\author{
(D) Jacob Nordman ${ }^{1,2}$ and (1D Zheng Li ${ }^{1}$
}

https://doi.org/10.1523/ENEURO.0331-20.2020

\begin{abstract}
${ }^{1}$ Section on Synapse Development Plasticity, National Institute of Mental Health, National Institutes of Health, Bethesda, MD 20892 and ${ }^{2}$ National Institute of General Medical Sciences, National Institutes of Health, Bethesda, MD 20892
\end{abstract}

\begin{abstract}
The dorsal raphe (DR) is an evolutionarily conserved brain structure that is involved in aggressive behavior. It projects onto numerous cortical and limbic areas underlying attack behavior. The specific neurocircuit through which the DR regulates aggression, however, is largely unclear. In this study we show that DR neurons expressing $\mathrm{CaMKIl} \alpha$ are activated by attack behavior in mice. These neurons project to the medial aspect of the orbitofrontal cortex (OFC; MeOC) and the medial amygdala (MeA), two key regions within the neural circuit known to control aggressive behavior. Using an in vivo optogenetic approach, we show that attack bouts are shortened by inhibiting CaMKIl $\alpha^{+}$neurons in the DR and their axons at the MeOC and prolonged by stimulating the DR-MeOC axons during an attack. By contrast, stimulating the axons of CaMKII $\alpha^{+}$DR neurons at the MeA shortens attack. Notably, neither the DR-MeOC or DR-MeA pathway initiates attack when stimulated. These results indicate that the DR-MeOC and DR-MeA pathways regulate the duration of attack behavior in opposite directions, revealing a circuit mechanism for the control of attack by the DR.
\end{abstract}

Key words: aggression; dorsal raphe; medial amygdala; neurocircuit; optogenetics; orbitofrontal cortex

\section{Significance Statement}

The dorsal raphe (DR) is a major node in the brain circuit regulating multiple attack behaviors. The underlying neurocircuitry through which the DR acts on aggression, however, remains elusive. Here, we show that the DR regulates the duration of attack through the medial orbitofrontal cortex (OFC; MeOC) and the medial amygdala (MeA), areas known to play a key role in aggression. While neither pathway is sufficient to initiate an attack, silencing the DR-MeOC pathway or activating the DR-MeA pathway shortens an attack, and stimulation of the DR-MeOC circuit prolongs an already occurring attack. These findings identify two DR-mediated neural circuits that regulate attack behavior.

\section{Introduction}

The dorsal raphe (DR) nucleus is one of the raphe nuclei located on the midline of the brainstem. It is a phylogenetically conserved structure and plays a role in various types of aggressive behaviors, such as maternal and territorial aggression in rodents (Walletschek and Raab, 1982; Takahashi and Miczek, 2014; Holschbach et al., 2018;

Received July 27, 2020; accepted September 25, 2020; First published October 14, 2020.

The authors declare no competing financial interests.
Muroi and Ishii, 2019). The role of the DR in aggression is complex and context dependent. For example, infusion of glutamate in the DR increases the frequency of attack bites against a conspecific, but with no effect on threatening behavior (Takahashi et al., 2015). Conversely, infusion of glutamate receptor agonists increases bite latency and decreases bite frequency in maternal aggression, with no effect on chasing behavior (Muroi and Ishii, 2019). Knock-

Author contributions: J.N. and Z.L. designed research; J.N. performed research; J.N. analyzed data; J.N. and Z.L. wrote the paper. 
down of tyrosine receptor kinase receptors in DR neurons decreases latency to attack (Adachi et al., 2017). Prepartum lesion of the DR decreases the frequency of attack in maternal aggression, while postpartum lesion of the DR decreases the duration of an individual attack bout (Holschbach et al., 2018).

The DR contains a heterogenous population of neurons that release one or a combination of the neurotransmitters serotonin (5-hydroxytryptamine or 5-HT), dopamine, glutamate and GABA (Liu et al., 2014; Ren et al., 2018; Huang et al., 2019). Glutamatergic neurons of the DR innervate dopamine neurons of the ventral tegmental area (VTA) to reinforce instrumental responding and establish conditioned place preference (Qi et al., 2014). GABAergic interneurons of the DR mediate the acquisition of avoidance after social defeat, as demonstrated by optogenetic silencing of the GABAergic input to local 5-HT neurons (Challis et al., 2013). Dopaminergic neurons of the DR are required for rebound sociability after social isolation (Matthews et al., 2016). The serotonergic neurons of the DR are involved in aggressive behavior. In mice with reduced 5-HT release at the DR, defensive but not offensive aggression increases as determined by counter-attack bites (Chen et al., 1994). In maternal aggression, activation of 5-HT1A somatodendritic autoreceptors in the DR promotes lateral attacks, but with no effect on threatening behavior (da Veiga et al., 2011). Studies linking the DR to aggression are largely confined to the 5-HT neurons (Olivier, 2004; Nelson, 2006; Nelson and Trainor, 2007). The role of other DR cell types in aggression is unclear.

The prefrontal cortex and amygdala are densely innervated by the DR (Wilson and Molliver, 1991; Clarke et al., 2007; Ren et al., 2018). The orbitofrontal cortex (OFC) and medial amygdala (MeA) are subregions within these areas that receive DR inputs (Cádiz-Moretti et al., 2016; Murphy and Deutch, 2018; Ren et al., 2018) and regulate intermale aggression (Blair, 2004; Siever, 2008; Rosell et al., 2010; Hong et al., 2014; Rosell and Siever, 2015; Unger et al., 2015; Buades-Rotger et al., 2017; Haller, 2018). DR neurons projecting to the OFC and the MeA may control attack behavior in different ways. In support of this hypothesis, 5-HT signaling, the majority of which derives from neurons in the raphe, at the OFC and MeA appears to have different effects on attack behavior. In subsets of individuals with personality disorder that exhibit impulsive aggression 5-HT2A expression is increased at the OFC, as determined by positron emission tomography of a 5HT2AR radioligand, while infusion of agonists of 5-HT1B

This work was supported by the Intramural Research Program of the National Institute of Mental Health Grant 1Z1AMH002881 (to Z.L.) and the National Institute of General Medical Sciences Postdoctoral Research Associate Training (PRAT) Program 1FI2GM119962-01 (to J.N.).

Acknowledgements: We thank Daniel Letchford, Lindsay Ejoh, Princess Miranda, and Winnie Gao for analysis of behavioral data.

Correspondence should be addressed to Zheng Li at lizheng2@mail.nih.gov. https://doi.org/10.1523/ENEURO.0331-20.2020 Copyright (C) 2020 Nordman and Li

This is an open-access article distributed under the terms of the Creative Commons Attribution 4.0 International license, which permits unrestricted use, distribution and reproduction in any medium provided that the original work is properly attributed. autoreceptors, which inhibits $5-\mathrm{HT}$ release, at the OFC suppresses attack behavior in mice (De Almeida et al., 2006; Rosell et al., 2010). Conversely, stimulation of 5HT2A receptors in the MeA suppresses shock-induced attack behavior and muricide, while inhibition of 5-HT2 receptors enhances it (Rodgers, 1977; Puciłowski et al., 1985). These findings suggest that DR input promotes attack at the OFC but suppresses attack at the MeA. A direct manipulation of the DR projections to the OFC and $\mathrm{MeA}$ is necessary to tease apart their specific roles in aggressive behavior.

Using an in vivo optogenetic approach, we show that CaMKII $\alpha^{+}$neurons in the DR are activated by attack and that these neurons modulate the duration of attack behavior toward an intruder through two projection areas. Specifically, the DR-medial OFC (MeOC) pathway prolongs an already occurring attack, while the DR-MeA pathway shortens it. These findings reveal two DR-mediated neurocircuits that have divergent functions in aggressive behavior.

\section{Materials and Methods}

\section{Animals and reagents}

All animal protocols were approved by the Animal Care and Use Committee (ACUC). Five-week-old C57BL/6 male mice were purchased from Charles River and housed under a 12-h light (9 P.M. to 9 A.M.)/12-h dark (9 A.M. to 9 P.M.) cycle with ad libitum access to water and food. All mice were individually housed for three weeks before testing to increase aggression (Malick, 1979; Valzelli, 1985). Smaller, submissive, male mice group housed with littermates were used as intruders to promote aggressive behavior in resident mice (Koolhaas et al., 2013). Intruder mice did not attack during aggression tests in this study. Reagents are listed in Table 1.

\section{Surgery}

Six- to seven-week-old C57BL/6 male mice were anaesthetized with isoflurane (3\% for induction and $1 \%$ for maintenance) and then placed onto a stereotaxic frame (David Kopf Instruments). Craniotomy was made and $500 \mathrm{nl}$ virus (AAV2/9-CaMKIl $\alpha$ (1.3 kb variant)-ChR2 (E123A)-mCherry, AAV2/9-CaMKII $\alpha$ (1.3 kb variant)-ChR2 (E123A)-EYFP, AAV2/9-CaMKII $\alpha$ (1.3 kb variant)-ArchTEYFP or the lentiviral vector pRRIsin.CMV:eGFP as control virus) was injected into the center of the DR (beginning at skull surface, bregma coordinates: $-4.3 \mathrm{~mm}$ AP, 1.10 $\mathrm{mm} \mathrm{ML},-2.85 \mathrm{~mm} \mathrm{DV}, 20^{\circ} \mathrm{ML}$ angle) using a $5-\mu \mathrm{l}$ gastight Hamilton syringe (33-gauge, beveled needle) at a rate of $75 \mathrm{nl} / \mathrm{min}$. The ChR2 (E123A)-EYFP used in this study is the ultrafast opsin variant $\operatorname{ChETA}(\mathrm{A})$ (Gunaydin et al., 2010; Mattis et al., 2011). After injection, the needle was left in place for an additional $5 \mathrm{~min}$ and then slowly withdrawn. After viral injection, ferrule-terminated optical fibers (100 $\mu \mathrm{m}$ in diameter, ThorLabs) were placed $100 \mu \mathrm{m}$ above the viral injection site at the DR or bilaterally above the MeOC (beginning at skull surface, bregma coordinates: $+2.4 \mathrm{~mm} \mathrm{AP},+/-1.7 \mathrm{~mm} \mathrm{ML},-1.7 \mathrm{~mm} \mathrm{DV}$ ) or the MeA (beginning at skull surface, bregma coordinates: $-1.5 \mathrm{~mm} \mathrm{AP},+/-2.1 \mathrm{~mm} \mathrm{ML},-5 \mathrm{~mm} \mathrm{DV})$. Optical 
Table 1. Key resources table

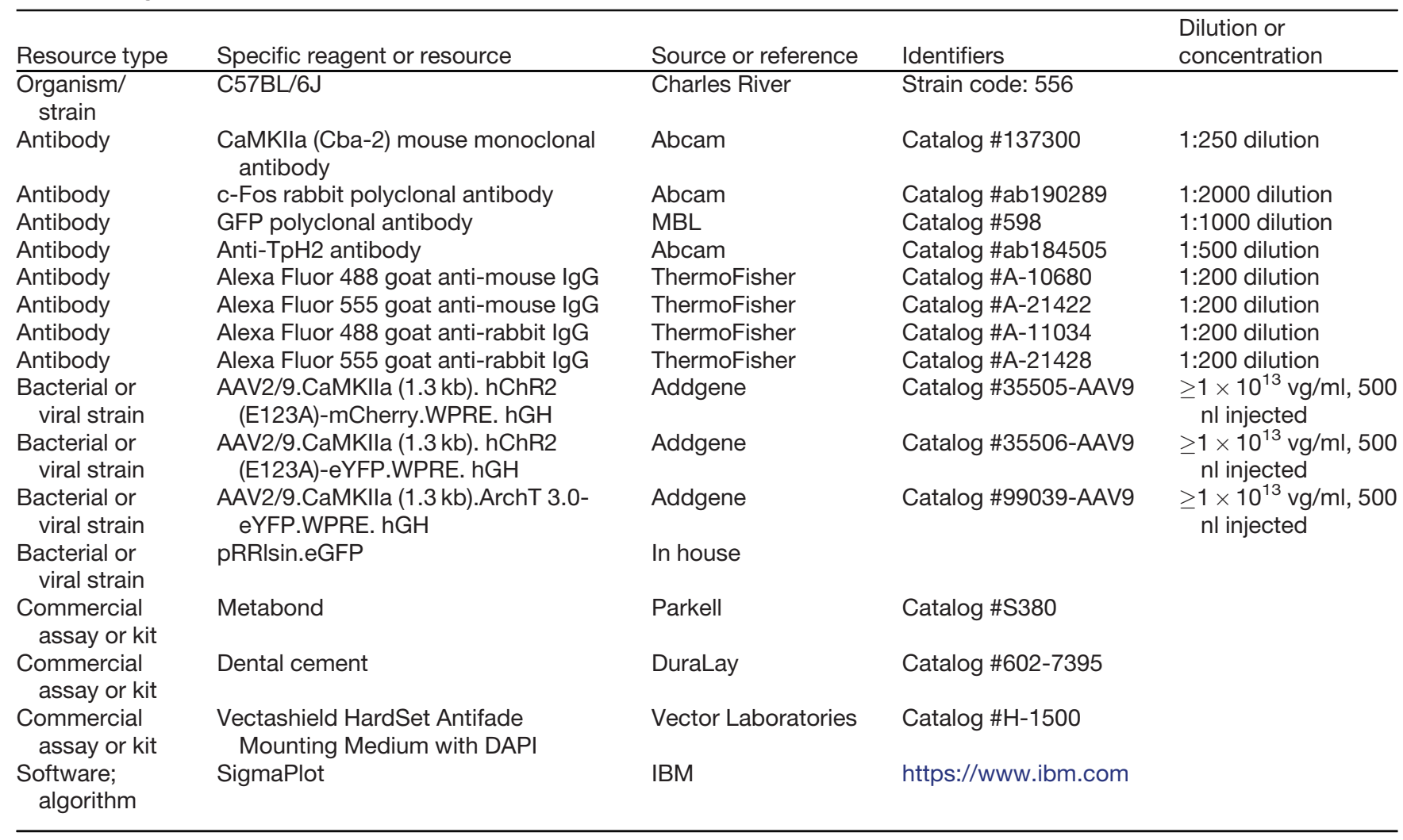

fibers were secured to the skull using Metabond (Parkell), stainless steel screws (PlasticsOne) and dental cement (DuraLay). After surgery, mice recovered on a heated pad until ambulatory and then were returned to their home cage for six weeks before optical stimulation.

\section{Resident intruder (RI) test}

Before the RI test, mice were individually housed for three weeks. All behavioral experiments took place during the dark cycle of the day, as this is the main activity phase of the mouse (Koolhaas et al., 2013). On the day of testing, mice were transferred in their home cage to a behavioral test room and allowed to acclimate for at least $1 \mathrm{~h}$. Younger, group-housed target conspecific males were placed into the home cage of the resident mouse and the two were allowed to freely interact for $10 \mathrm{~min}$. All animals were allowed to habituate to the patch cord for $20 \mathrm{~min}$ before introduction of the conspecific. Baseline aggression was tested at 1-4 d before the RI test. Animal behavior was captured with a video camera. If excessive tissue damage occurred, the test was prematurely terminated and not analyzed. Excessively aggressive mice, as determined by total attack time $>40 \%$ during the RI test, were eliminated from further analysis (Hong et al., 2014; Nordman et al., 2020a). Videos of behavioral tests were reviewed and hand scored by a researcher blind to the experimental conditions using a bin size of $0.5 \mathrm{~s}$. Aggressive behaviors were identified as chasing, boxing, pinning, biting, and wrestling (Blanchard and Blanchard, 1977; Lin et al., 2011; Koolhaas et al., 2013; Hong et al., 2014; Golden et al., 2016).

\section{In vivo optogenetic stimulation}

Optogenetic stimulation was performed via an optical fiber (ferrule fiber, ThorLabs) connected through a zirconia split sleeve and patch cord to a $473 \mathrm{~nm}$ laser (Coherent) or a $561 \mathrm{~nm}$ laser (CrystaLaser) under the control of an Optogenetics TTL Pulse Generator (Doric Lenses). Mice expressing ChR2 were stimulated for $5 \mathrm{~ms}$ using 1- to 3$\mathrm{mW} 473 \mathrm{~nm}$ light pulsed at $10 \mathrm{~Hz}$ for $10 \mathrm{~s}$. Mice expressing ArchT were delivered a 1- to 3-mW continuous 10-s $561 \mathrm{~nm}$ light pulse. Laser was manually turned on and the frequency and duration of light pulses were controlled by Doric Studio software (Doric).

\section{Immunohistochemistry}

Mice were transcardially perfused with $4 \%$ paraformaldehyde in PBS solution. Brains were removed and postfixed at $4^{\circ} \mathrm{C}$ overnight, then cryoprotected overnight in $15 \%$ sucrose (in PBS) followed by $30 \%$ sucrose in PBS. Brains were cut into $30-\mu \mathrm{m}$-thick sections using a cryostat (Leica CM3050-S), then either mounted onto silanized slides (KD Medical) or stored in PBS as floating sections for immunohistochemistry or confirming the location of viral injection and implantation. For immunohistochemistry, free floating brain sections were heated to $80^{\circ} \mathrm{C}$ for $30 \mathrm{~min}$ in citrate buffer for antigen retrieval (Jiao et al., 1999) and then blocked with $10 \%$ goat serum and $1 \%$ bovine serum albumin in PBS with $0.03 \%$ Triton $X-100$ (PBS-T) for $3 \mathrm{~h}$ at room temperature. Sections were then stained for primary antibodies overnight at $4{ }^{\circ} \mathrm{C}$, followed by incubation with secondary antibodies for $1 \mathrm{~h}$ at room 
Table 2: Statistical table

\begin{tabular}{|c|c|c|c|c|c|c|}
\hline Data & Method & Factor & $n$ & $T, U$, or $F$ stat & $p$ value & Post hoc correction \\
\hline Fig. 1C & Mann-Whitney & Resident vs control & 6,7 & $U=2$ & 0.008 & \\
\hline Fig. $1 D$ & Mann-Whitney & Resident vs control & 6,7 & $U=5$ & 0.027 & \\
\hline Fig. $1 E$ & Student's $t$ test & Resident vs control & 6,7 & $T_{(11)}=0.164$ & 0.872 & \\
\hline Fig. $1 F$ & Student's $t$ test & Resident vs control & 6,7 & $T_{(11)}=0.062$ & 0.952 & \\
\hline \multirow[t]{3}{*}{ Fig. $1 H$} & One-way ANOVA & \# of cells at bregma -4.84 & 5,5 & $F_{(2,14)}=13.339$ & $<0.001$ & Tukey's \\
\hline & One-way ANOVA & \# of cells at bregma -4.60 & 5,5 & $F_{(2,14)}=6.357$ & 0.013 & Tukey's \\
\hline & One-way ANOVA & \# of cells at bregma -4.34 & 5,5 & $F_{(2,14)}=168.490$ & $<0.001$ & Tukey's \\
\hline \multirow[t]{3}{*}{ Fig. 1/ } & One-way ANOVA & $\%$ of DAPI at bregma -4.84 & 5,5 & $F_{(2,14)}=13.859$ & $<0.001$ & Tukey's \\
\hline & One-way ANOVA & $\%$ of cells at bregma -4.60 & 5,5 & $F_{(2,14)}=4.493$ & 0.035 & Tukey's \\
\hline & One-way ANOVA & $\%$ of cells at bregma -4.34 & 5,5 & $F_{(2,14)}=20.455$ & $<0.001$ & Tukey's \\
\hline Fig. 2C & Mann-Whitney & ChR2 vs GFP & 6,6 & $U=0$ & 0.005 & \\
\hline Fig. 2D & Student's $t$ test & ChR2 vs GFP & 6,6 & $T_{(10)}=0.203$ & 0.843 & \\
\hline \multirow[t]{2}{*}{ Fig. 2G } & One-way ANOVA & TpH2 vs ChR2 & 5,5 & $F_{(2,17)}=13.714$ & $<0.001$ & Tukey's \\
\hline & One-way ANOVA & TpH2 vs ArchT & 5,5 & $F_{(2,17)}=20.868$ & $<0.001$ & Tukey's \\
\hline Fig. $2 K$ & Student's $t$ test & Opsin vs GFP & 5,4 & $T_{(7)}=0.793$ & 0.454 & \\
\hline \multirow[t]{2}{*}{ Fig. 20} & Student's $t$ test & Before light onset (10 s) & 5,4 & $T_{(7)}=-0.607$ & 0.563 & \\
\hline & Student's $t$ test & During light (10 s) & 5,4 & $T_{(7)}=0.882$ & 0.407 & \\
\hline \multirow[t]{2}{*}{ Fig. 2S } & Student's $t$ test & Before light onset (10 s) & 5,3 & $T_{(6)}=0.136$ & 0.896 & \\
\hline & Student's $t$ test & During light (10 s) & 5,3 & $T_{(6)}=-10.784$ & $<0.001$ & \\
\hline \multirow[t]{3}{*}{ Fig. $3 L$} & Student's $t$ test & ChR2 vs GFP at bregma 2.68 & 6,6 & $T_{(10)}=0.325$ & 0.752 & \\
\hline & Student's $t$ test & ChR2 vs GFP at bregma 2.68 & 6,6 & $T_{(10)}=0.890$ & 0.346 & \\
\hline & Student's $t$ test & ChR2 vs GFP at bregma 2.34 & 6,6 & $T_{(10)}=0.396$ & 0.701 & \\
\hline \multirow[t]{3}{*}{ Fig. $3 M$} & Student's $t$ test & ChR2 vs GFP at bregma 2.34 & 6,6 & $T_{(10)}=8.033$ & $<0.001$ & \\
\hline & Student's $t$ test & ChR2 vs GFP at bregma 2.10 & 6,6 & $T_{(10)}=3.850$ & 0.003 & \\
\hline & Student's $t$ test & ChR2 vs GFP at bregma 2.10 & 6,6 & $T_{(10)}=7.965$ & $<0.001$ & \\
\hline Fig. $4 L$ & Student's $t$ test & ChR2 vs GFP & 6,6 & $T_{(10)}=0.474$ & 0.646 & \\
\hline Fig. $4 M$ & Student's $t$ test & ChR2 vs GFP & 6,6 & $T_{(10)}=0.558$ & 0.589 & \\
\hline Fig. $4 N$ & Student's $t$ test & ChR2 vs GFP & 6,6 & $T_{(10)}=0.258$ & 0.801 & \\
\hline Fig. 40 & Student's $t$ test & ChR2 vs GFP & 6,6 & $T_{(10)}=1.100$ & 0.297 & \\
\hline Fig. $4 P$ & Student's $t$ test & ChR2 vs GFP & 6,6 & $T_{(10)}=1.203$ & 0.257 & \\
\hline Fig. 4Q & Student's $t$ test & ChR2 vs GFP & 6,6 & $T_{(10)}=4.693$ & $<0.001$ & \\
\hline Fig. $4 R$ & Student's $t$ test & ChR2 vs GFP & 6,6 & $T_{(10)}=2.745$ & 0.021 & \\
\hline Fig. $4 S$ & Student's $t$ test & ChR2 vs GFP & 6,6 & $T_{(10)}=3.104$ & 0.011 & \\
\hline Fig. $4 T$ & Student's $t$ test & ChR2 vs GFP & 6,6 & $T_{(10)}=1.597$ & 0.141 & \\
\hline Fig. $4 U$ & Student's $t$ test & ChR2 vs GFP & 6,6 & $T_{(10)}=2.525$ & 0.030 & \\
\hline Fig. 5D & Student's $t$ test & Opsin vs GFP & 4,3 & $T_{(5)}=1.101$ & 0.321 & \\
\hline \multirow[t]{2}{*}{ Fig. $5 H$} & Student's $t$ test & Before light onset (10 s) & 4,3 & $T_{(5)}=0.845$ & 0.437 & \\
\hline & Mann-Whitney & During light (10 s) & 4,3 & $U=28$ & 0.952 & \\
\hline \multirow[t]{2}{*}{ Fig. 5L } & Student's $t$ test & Before light onset (10 s) & 4,3 & $T_{(5)}=0.632$ & 0.555 & \\
\hline & Student's $t$ test & During light (10 s) & 4,3 & $T_{(5)}=-6.606$ & $<0.001$ & \\
\hline Fig. $6 D$ & Student's $t$ test & Opsin vs GFP & 5,4 & $T_{(7)}=0.137$ & 0.895 & \\
\hline \multirow[t]{2}{*}{ Fig. $6 H$} & Student's $t$ test & Before light onset (10 s) & 4,3 & $T_{(5)}=0.845$ & 0.437 & \\
\hline & Mann-Whitney & During light (10 s) & 4,3 & $T_{(5)}=0$ & 1.000 & \\
\hline \multirow[t]{2}{*}{ Fig. $6 L$} & Student's $t$ test & Before light onset (10 s) & 6,4 & $T_{(8)}=-1.217$ & 0.278 & \\
\hline & Student's $t$ test & During light (10 s) & 6,4 & $T_{(8)}=0.743$ & 0.491 & \\
\hline Fig. 7D & Student's $t$ test & Opsin vs GFP & 4,3 & $T_{(5)}=1.130$ & 0.310 & \\
\hline \multirow[t]{2}{*}{ Fig. $7 H$} & Student's $t$ test & Before light onset (10 s) & 4,3 & $T_{(5)}=1.425$ & 0.214 & \\
\hline & Student's $t$ test & During light (10 s) & 4,3 & $T_{(5)}=8.871$ & $<0.001$ & \\
\hline Fig. $7 L$ & Student's $t$ test & Opsin vs GFP & 6,4 & $T_{(8)}=1.010$ & 0.342 & \\
\hline \multirow[t]{2}{*}{ Fig. $7 P$} & Student's $t$ test & Before light onset (10 s) & 6,4 & $T_{(8)}=0.229$ & 0.826 & \\
\hline & Student's $t$ test & During light (10 s) & 6,4 & $T_{(8)}=-12.538$ & $<0.001$ & \\
\hline
\end{tabular}

temperature. Sections were mounted to slides with Vectashield HardSet Antifade Mounting Medium containing DAPI.

\section{Image acquisition and analysis}

Brain slices were imaged with a multi-slide fluorescent microscope (Zeiss Axio Scan) with a $10 \times$ (NA 0.45) objective to locate the areas with fluorescence signals, and then a laser scanning confocal microscope (Zeiss
LSM510 and LSM780) with a $40 \times$ (NA 1.3 oil immersion) objective for high-magnification imaging in the region of interest. Z-stack confocal images were collapsed and analyzed with ImageJ by a researcher blind to the experimental conditions. c-Fos positive cells were identified using the "Analyze Particles" function of ImageJ and validated as cells by their overlap with DAPI. Cells co-labeled for DAPI and CaMKIl $\alpha$ and/or c-Fos were manually counted by a researcher blind to the experimental conditions. 
A
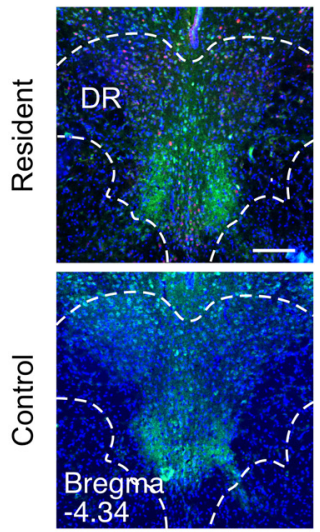

C

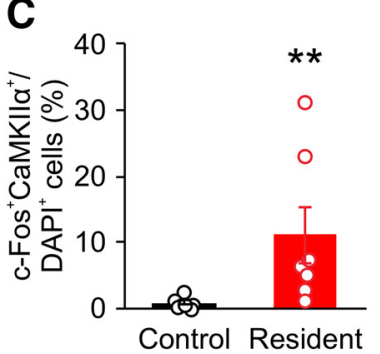

DAPI
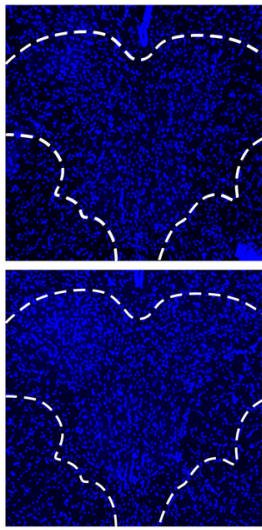

D

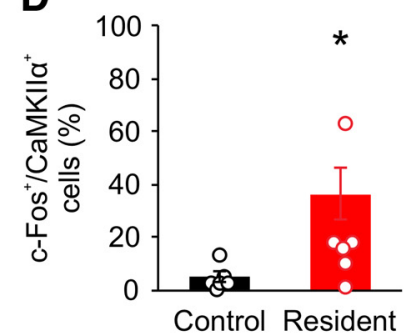

G Bregma -4.84
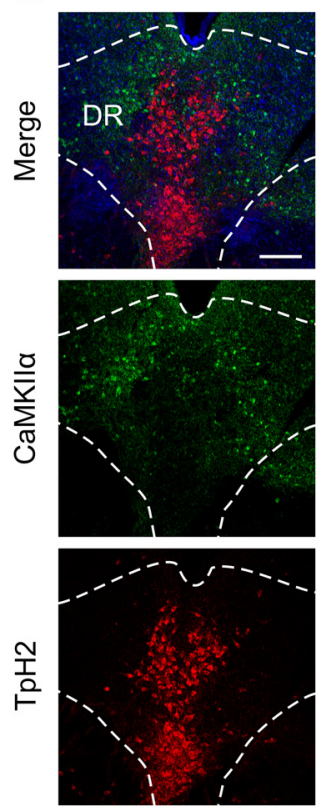

Bregma -4.60
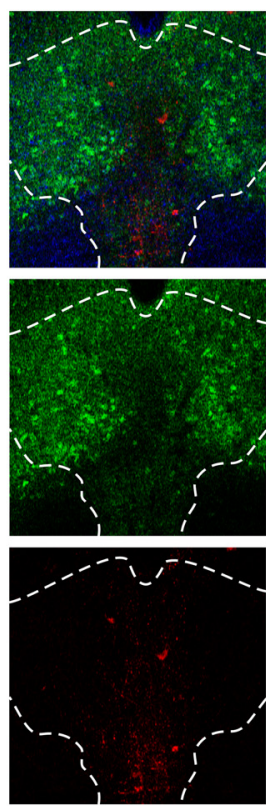

CaMKIIa
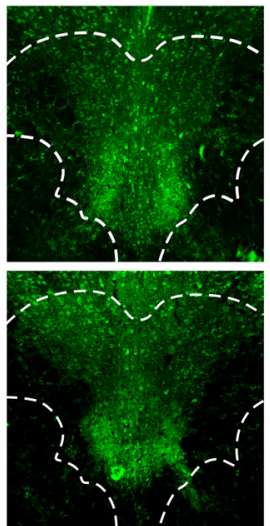

Control Resident

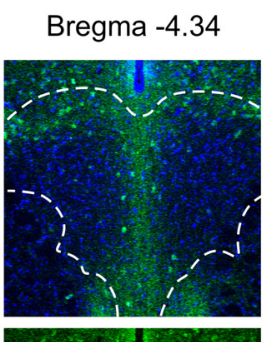

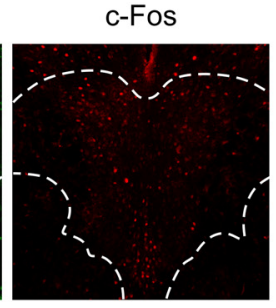

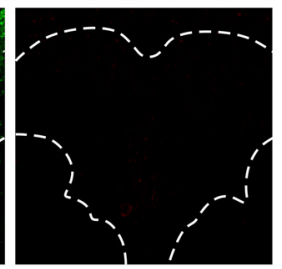

E

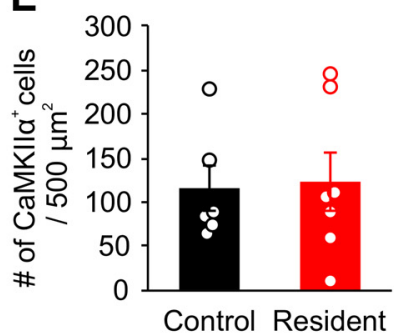

B
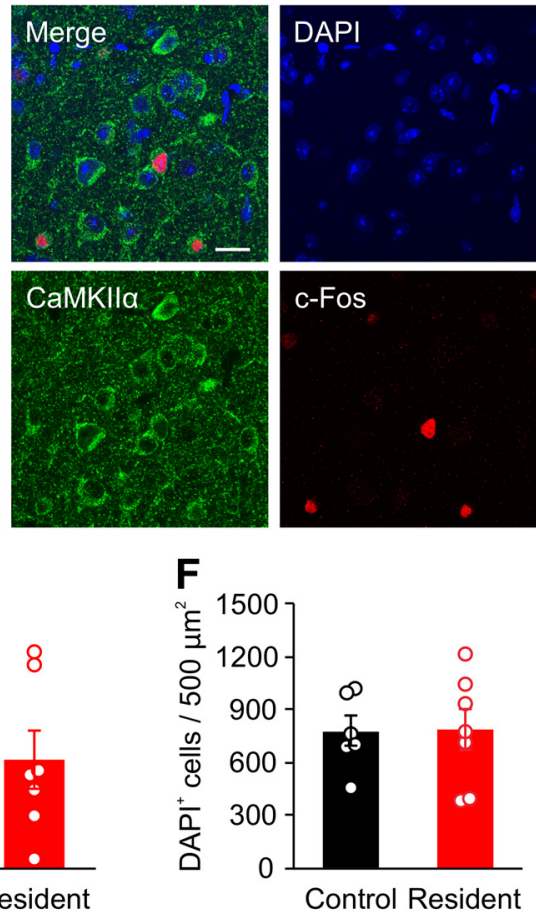

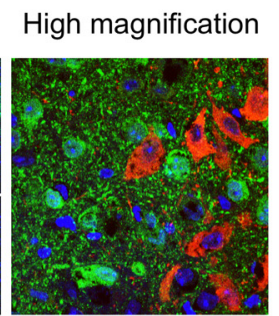

H

CaMKIIa (6)

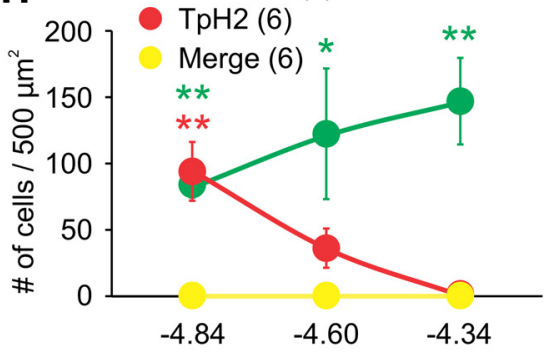

From bregma $(\mathrm{mm})$

I

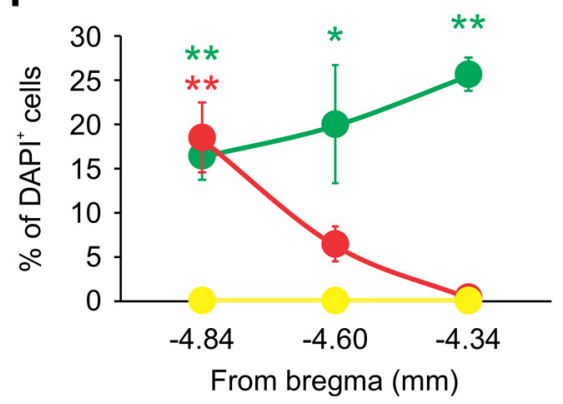

Figure 1. CaMKII $\alpha^{+}$neurons of the DR are activated by attack. $\boldsymbol{A}-\boldsymbol{F}$, Mice (10 weeks of age) were examined for aggression using the RI assay. Mice were perfused $60 \mathrm{~min}$ after the assay for immunostaining. $\boldsymbol{A}$, Representative images of brain sections stained for $\mathrm{c}$-Fos and CaMKIl $\alpha$ in the DR from resident or control animals $1 \mathrm{~h}$ after the RI test. $\boldsymbol{B}$, Representative high-magnification images of CaMKIll $\alpha^{+}$cells in the DR that were positive for c-Fos. $\boldsymbol{C}, \boldsymbol{D}$, Percentage of c-Fos ${ }^{+}$cells that colocalize with CaMKIl $\alpha^{+}$and DAPI ${ }^{+}$cells in resident and control mice for $\boldsymbol{A}$. $\boldsymbol{E}, \boldsymbol{F}$, Quantification of $\mathrm{CaMKII}^{+}(\boldsymbol{E})$ and $\mathrm{DAPI}^{+}(\boldsymbol{F})$ cells in the DR in resident and control mice. $\mathbf{G}$, Representative images of brain sections stained for $\mathrm{CaMKIl} \alpha$ and $\mathrm{TpH} 2$ throughout the DR (bregma -4.34 to $-4.84 \mathrm{~mm}$ ). High-magnification image of the $\mathrm{DR}$ is taken from a brain slice at bregma position -4.84 , as this is where the majority of $\mathrm{TpH} 2^{+}$cells can be found. $\boldsymbol{H}$, Quantification of total number of $\mathrm{CaMKII}^{+}$and $\mathrm{TpH}_{2}{ }^{+}$cells in the DR. Asterisks indicate statistical significance of $\mathrm{CaMKIl} \alpha$ (green) or TpH2 (red) from merged set at the specified coordinate. One slice was quantified per area per animal. Animal number is indicated in parentheses. $\boldsymbol{I}$, Percentage of $\mathrm{DAPI}^{+}$cells in the DR that co-label for CaMKIl $\alpha$ and $\mathrm{TpH} 2$. Asterisks indicate statistical significance of CaMKIl $\alpha$ (green) or $\mathrm{TpH} 2$ (red) from merged set at the specified coordinate. Only cells within the DR were counted. Scale bars: $200 \mu \mathrm{m}(\boldsymbol{A}, \boldsymbol{G})$ and $25 \mu \mathrm{m}(\boldsymbol{B})$. Data are presented as mean $\pm \mathrm{SEM} * p<0.05, * * p<0.01$. Statistics can be found in Table 2 . 

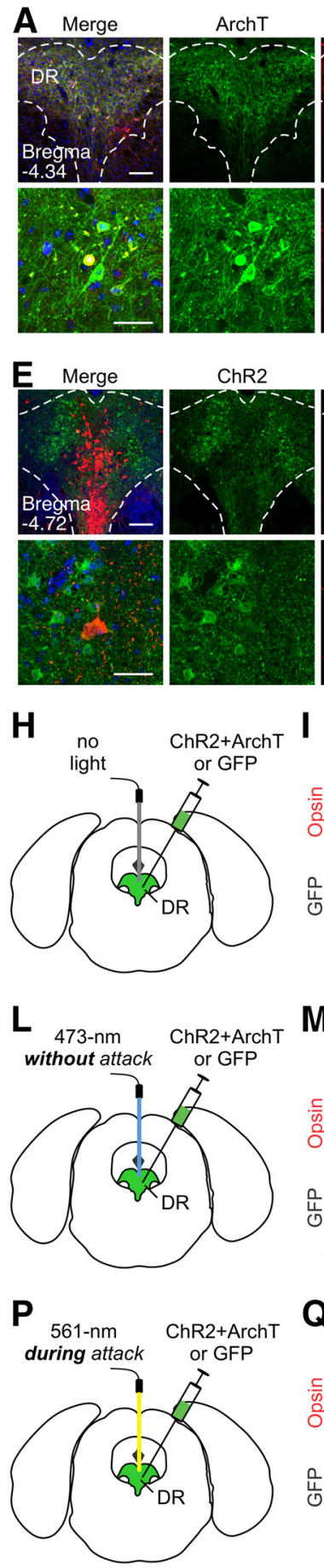
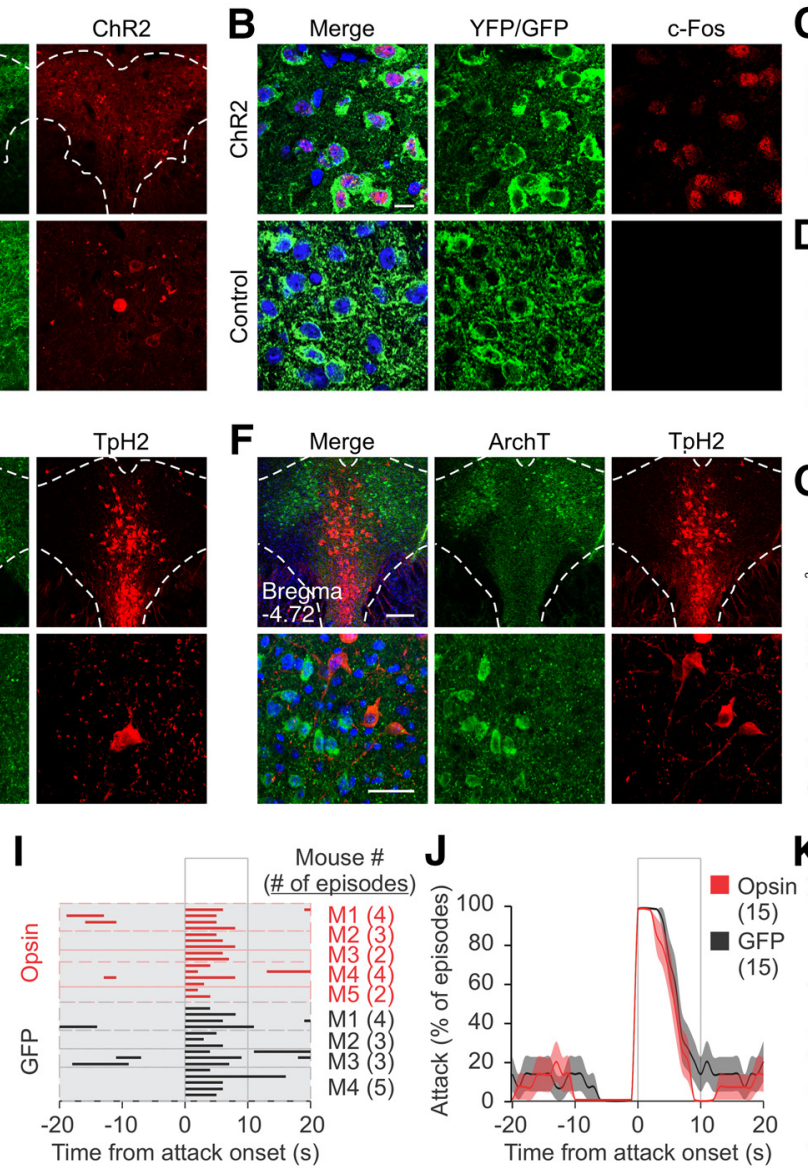

Time from attack onset (s)

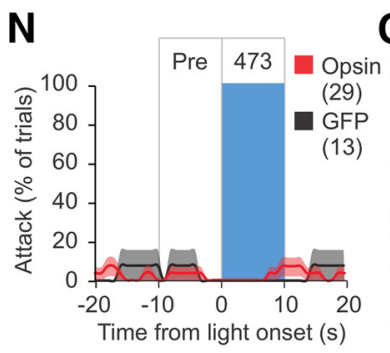

R
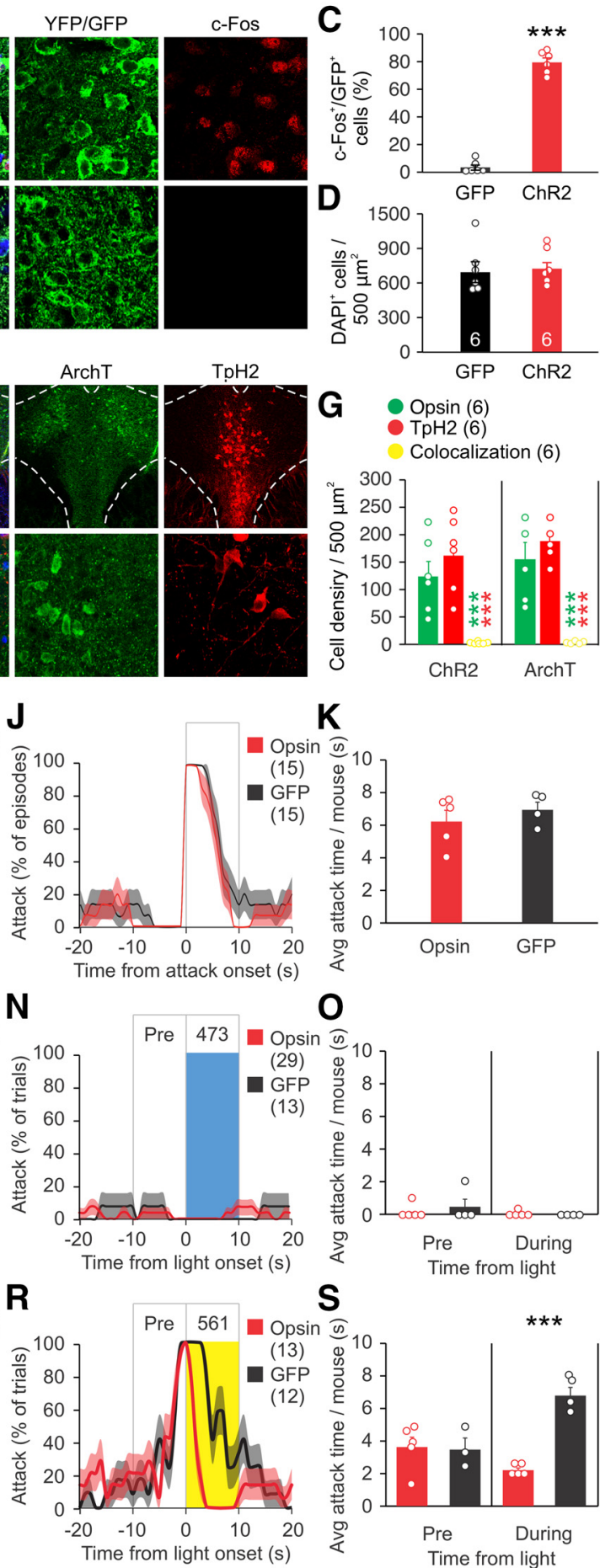

GFP ChR2
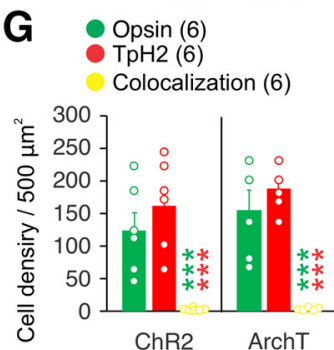

K

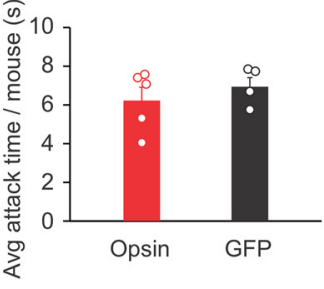

0

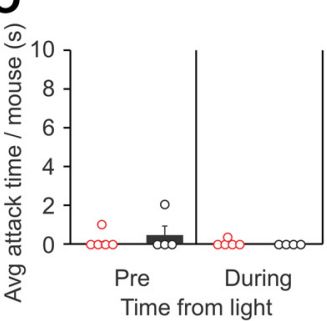

$\mathbf{S}$
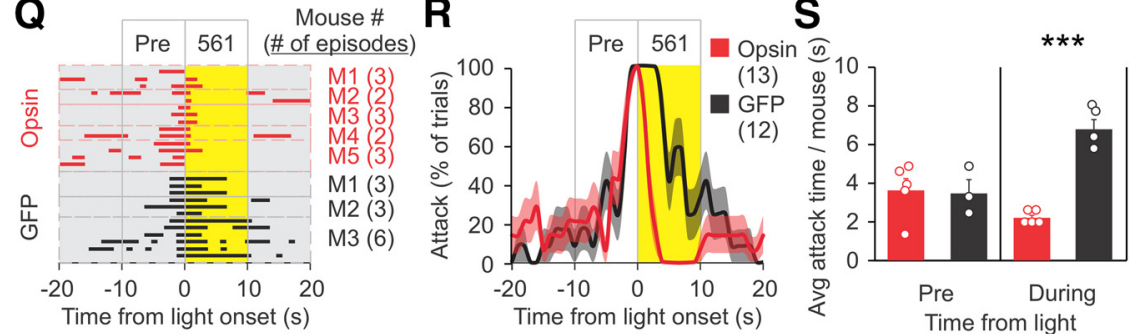

Figure 2. Inhibition of CaMKII $\alpha^{+}$DR neurons shortens attack. $\boldsymbol{A}$, Representative high-magnification and low-magnification images of ChR2-mCherry and ArchT-EYFP expression in the DR three weeks after viral injection. $\boldsymbol{B}$, Representative images of brain sections stained for c-Fos in the DR of mice injected with ChR2-EYFP or GFP and photostimulated with $473 \mathrm{~nm}$ light (pulsed at $10 \mathrm{~Hz}$ for 10 s). $\boldsymbol{C}, \boldsymbol{D}$, Percentage of $\mathrm{YFP}^{+}$or $\mathrm{GFP}^{+}$cells that colocalize with c-Fos $(\boldsymbol{C})$ and quantification of total $\mathrm{DAPI}^{+}$cells $(\boldsymbol{D})$ in the DR after photostimulation for $\boldsymbol{B}$. Only cells within the DR were counted. $\boldsymbol{E}, \boldsymbol{F}$, Representative images of brain sections expressing ChR2 (E) or ArchT $(\boldsymbol{F})$ under the CaMKIl $\alpha$ promoter co-stained for TpH2 in the DR. G, Quantification of ChR2 or ArchT (opsin) expressing cells that were stained positive for $\mathrm{TpH} 2$. Only cells within the DR were counted. One slice was quantified per area per animal. Animal number is indicated in parentheses. $\boldsymbol{H}, \boldsymbol{L}, \boldsymbol{P}$, Schematic drawing of viral injection (AAV expressing ChR2 and ArchT or GFP control virus), placement of optic fiber, and stimulation procedure. Opsin expressing mice in $\boldsymbol{H}-\boldsymbol{K}$ and opsin stimulated mice in L-S were injected with ChR2 virus and ArchT virus. The same mice were stimulated with 473 or $561 \mathrm{~nm}$ light on separate days. I, Raster plots of attack events during each interaction episode (rows in the raster plot, defined as the period from $20 \mathrm{~s}$ before to $20 \mathrm{~s}$ after the onset of a spontaneous attack) for each mouse. All attack events during the testing period are shown. $\boldsymbol{J}$, \% of episodes (rows) in 
continued

which mice attacked at each time point in I; red and dark lines indicate the mean, pink and gray areas indicate SEM. $\boldsymbol{K}$, Quantification of average attack time per mouse during the $10 \mathrm{~s}$ after the onset of a spontaneous attack, as represented in the boxed area in $\boldsymbol{J}$. $\boldsymbol{M}$, Raster plots of trials (rows) of mice photostimulated with $473 \mathrm{~nm}$ light at the DR when the mouse was not attacking. All trials are aligned to the onset of light. $\boldsymbol{N}, \%$ of trials in which mice attacked at each time point in $\boldsymbol{M}$; red and dark lines indicate the mean, pink and gray areas indicate SEM. $\mathbf{O}$, Quantification of attack time per mouse before and during light stimulation for $\boldsymbol{M}$. Q , Raster plots of trials (rows) of mice photostimulated with $561 \mathrm{~nm}$ light at the DR during an attack. All trials are aligned to onset of light. $\boldsymbol{R}, \%$ of trials in which mice attacked at each time point in $\boldsymbol{Q}$; red and dark lines indicate the mean, pink and gray areas indicate SEM. S, Quantification of attack time per mouse before and during light stimulation for $\boldsymbol{Q}$. Scale bars: $200 \mu \mathrm{m}$ (lowmagnification image; top; $\boldsymbol{A}, \boldsymbol{E}, \boldsymbol{F}$ ); $50 \mu \mathrm{m}$ (high-magnification image; bottom; $\boldsymbol{A}, \boldsymbol{E}, \boldsymbol{F}$ ); $10 \mu \mathrm{m}(\boldsymbol{B})$. Data are presented as mean \pm SEM; $* * * p<0.001$. Statistics can be found in Table 2.

\section{Statistical analysis}

All data were presented as individual data points and mean \pm SEM SigmaPlot software was used for statistical analysis. Data were tested for normality and equal variance. Student's $t$ test (for data that satisfied normal distribution and equal variance) and Mann-Whitney $U$ test (for data that did not satisfy normal distribution and equal variance) were used to compare two groups and one-way ANOVA was used to test for differences among three groups. Tukey's test was used for post hoc multiple comparisons to identify groups that were significantly different; $p<0.05$ was considered significant and all tests were two tailed. All statistical data can be found in Table 2 .

\section{Results}

Excitatory neurons have been found in the DR (Commons, 2009; Qi et al., 2014; Zhou et al., 2015; Ren et al., 2018; Huang et al., 2019) and implicated in aggression (Chen et al., 1994). To better assess their function in aggressive behavior, we exposed C57BL/6 mice (male, 10 weeks of age) to the $\mathrm{RI}$ test and stained brain sections of the resident mice with antibodies against c-fos, which labels activated neurons, and $\mathrm{CaMKIl} \alpha$, a protein primarily expressed by excitatory neurons but not GABAergic neurons in many brain regions (Benson et al., 1992; Jones et al., 1994; Liu and Jones, 1996). The number of cells within the DR that were doubly positive for CaMKII $\alpha$ and c-Fos significantly increased after the RI test, suggesting that $\mathrm{CaMKIl} \alpha^{+}$cells are activated by attack behavior (Fig. 1A-D). The total number of $\mathrm{CaMKII}^{+}$and DAPI ${ }^{+}$cells within the DR was comparable in resident and control mice (Fig. 1E,F). Because many DR cells co-release 5-HT and glutamate (Liu et al., 2014; Ren et al., 2018; Huang et al., 2019), we co-stained the DR sections for CaMKII $\alpha$ and the 5-HT cell marker tryptophan hydroxylase type $2(\mathrm{TpH} 2)$. No CaMKIl $\alpha^{+}$ cells co-localized with $\mathrm{TpH} 2$ throughout the DR, indicating that $\mathrm{CaMKII} \alpha^{+}$neurons in the DR are not serotonergic (Fig. 1G-l).

To determine the function of $\mathrm{CaMKII} \alpha^{+}$DR neurons in aggressive behavior, we opted for an optogenetic approach to alter their activities. Eight-week-old mice were injected with AAV expressing ChR2-mCherry (for neural activation) and ArchT-EYFP (for neural inhibition) under the CaMKIl $\alpha$ promoter into the DR for use in the RI test three weeks later. Overlapping expression of ChR2 and ArchT was detected in the DR (Fig. 2A). Photostimulation of the DR using $473 \mathrm{~nm}$ light (5-ms light pulsed at $10-\mathrm{Hz}$ for $10 \mathrm{~s}$ ) activated the DR neurons transduced with ChR2-
EYFP as determined by c-Fos staining (Fig. $2 B-D$ ), indicating that photostimulation is effective. Previous studies have found that the CaMKII $\alpha$ promoter in AAV vectors drives protein expression primarily in excitatory cells but in a few inhibitory neurons as well (Scheyltjens et al., 2015; Watakabe et al., 2015). We detected few cells transduced with ChR2 or ArchT under the CaMKIl $\alpha$ promoter that were $\mathrm{TpH}_{2}^{+}$(Fig. 2E-G), consistent with our finding that the CaMKII $\alpha^{+}$cells of the DR are not serotonergic (Fig. 1G-l).

We first assessed baseline aggression in mice expressing ChR2 and ArchT or GFP control virus without light stimulation. Attack duration was comparable in ChR2/ AchT and GFP mice, suggesting that expression of ChR2 and ArchT has no effect on baseline aggression (Fig. $2 \mathrm{H}-$ $K)$. To test the effect of light stimulation on aggression, light pulses were delivered to the DR; $473 \mathrm{~nm}$ light stimulation applied when the animal was not attacking did not increase attack behavior for the duration of the light pulse (Fig. 2L-O). However, $561 \mathrm{~nm}$ light stimulation (10-s constant light) delivered after attack had begun significantly reduced attack duration during the light pulse (Fig. $2 P-S$ ). Attack behavior during the 10-s prestimulation period did not differ between opsin and control mice (Fig. 2M-O,Q$S)$. These results indicate that inhibition of $\mathrm{CaMKIl} \alpha^{+} \mathrm{DR}$ neurons suppress ongoing attack.

\section{CaMKII $\alpha^{+}$DR neurons project to the $\mathrm{MeOC}$ and MeA to regulate aggression}

To investigate the circuit mechanism by which $\mathrm{CaMKII} \alpha^{+}$ DR neurons regulate attack behavior, we stimulated the DR axons in the OFC and MeA, two DR projection areas (CádizMoretti et al., 2016; Murphy and Deutch, 2018; Ren et al., 2018) involved in aggressive behavior (Blair, 2004; Siever, 2008; Rosell et al., 2010; Hong et al., 2014; Rosell and Siever, 2015; Unger et al., 2015; Buades-Rotger et al., 2017; Haller, 2018). Mice were injected with AAV expressing ChR2-EYFP into the DR (Figs. $3 A, B, 4 A, B$ ) and then examined for YFP expression in the OFC and MeA. YFP ${ }^{+}$DR axons were found in the $\mathrm{MeOC}$ and throughout the $\mathrm{MeA}$ (Figs. 3C-E, 4C-E). Photostimulation of the DR using 473 $\mathrm{nm}$ light (5-ms pulsed at $10 \mathrm{~Hz}$ for $10 \mathrm{~s}$ ) activated cells within both regions as determined by c-Fos staining (Figs. $3 F-M, 4 F-U)$. The MeA can be divided into three main subdivisions: the anterior $\mathrm{MeA}(\mathrm{MeAa})$, the posteriordorsal MeA (MeApd), and the posteriorventral MeA (MeApv), all of which are involved in aggressive behavior 

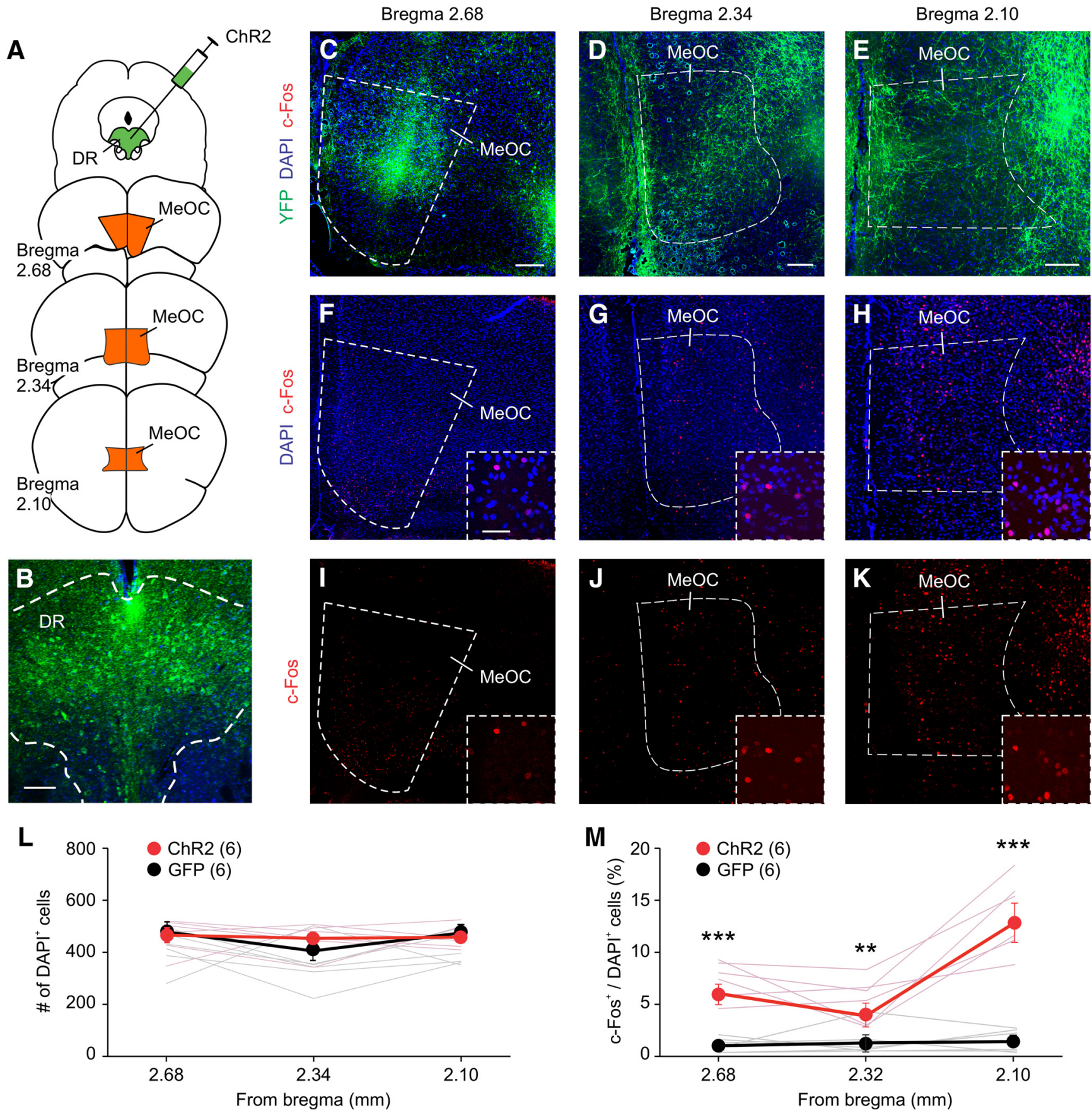

Figure 3. DR neurons project to and activate the MeOC. $\boldsymbol{A}-\boldsymbol{E}$, Schematic drawing of ChR2-EYFP viral injection and representative images of ChR2 expression in DR neurons $(\boldsymbol{B})$ and DR projections at the MeOC $(\boldsymbol{C}-\boldsymbol{E})$ three weeks later. $\boldsymbol{F}-\boldsymbol{K}$, C-Fos labeling of mice photostimulated at the DR-MeOC. $\boldsymbol{L}, \boldsymbol{M}$, Quantification of total number of cells $(\boldsymbol{L})$ and percentage $(\boldsymbol{M})$ of $^{c}-\mathrm{Fos}^{+}$cells in the MeOC for $\boldsymbol{D}-\boldsymbol{K}$. Only cells within the MeOC were counted. One slice was quantified per area per animal. Animal number is indicated in parentheses. Scale bars: $200 \mu \mathrm{m}(\boldsymbol{A}, \boldsymbol{B}$; low-magnification images in $\boldsymbol{C}, \boldsymbol{D})$ and $50 \mu \mathrm{m}$ (high-magnification images in $\boldsymbol{C}, \boldsymbol{D})$. Data are presented as mean $\pm \mathrm{SEM} ; * * p<0.01, * * * p<0.001$. Statistics can be found in Table 2 .

(Kollack-Walker and Newman, 1995; Lin et al., 2011; Hong et al., 2014; Miller et al., 2019; Nordman et al., 2020a). Analysis of c-Fos expression in the MeA revealed that all three regions are activated by photostimulation of the DR (Fig. $4 L-U$ ).

DR neurons were injected with ChR2-mCherry and ArchT-EYFP virus and then implanted with optical fibers into the $\mathrm{MeOC}$ or MeA (Figs. $5 A, E, I, 6 A, E, I)$. The RI test was performed eight weeks later. Baseline attacks in opsin and GFP mice were comparable (Figs. $5 B-D, 6 B-$ $D$ ). During the RI test, mice were stimulated with $473 \mathrm{~nm}$ light when not attacking or $561 \mathrm{~nm}$ light after attack had begun. As with the DR, $473 \mathrm{~nm}$ light stimulation at the $\mathrm{MeOC}$ or MeA did not increase attack behavior (Figs. 5E- 

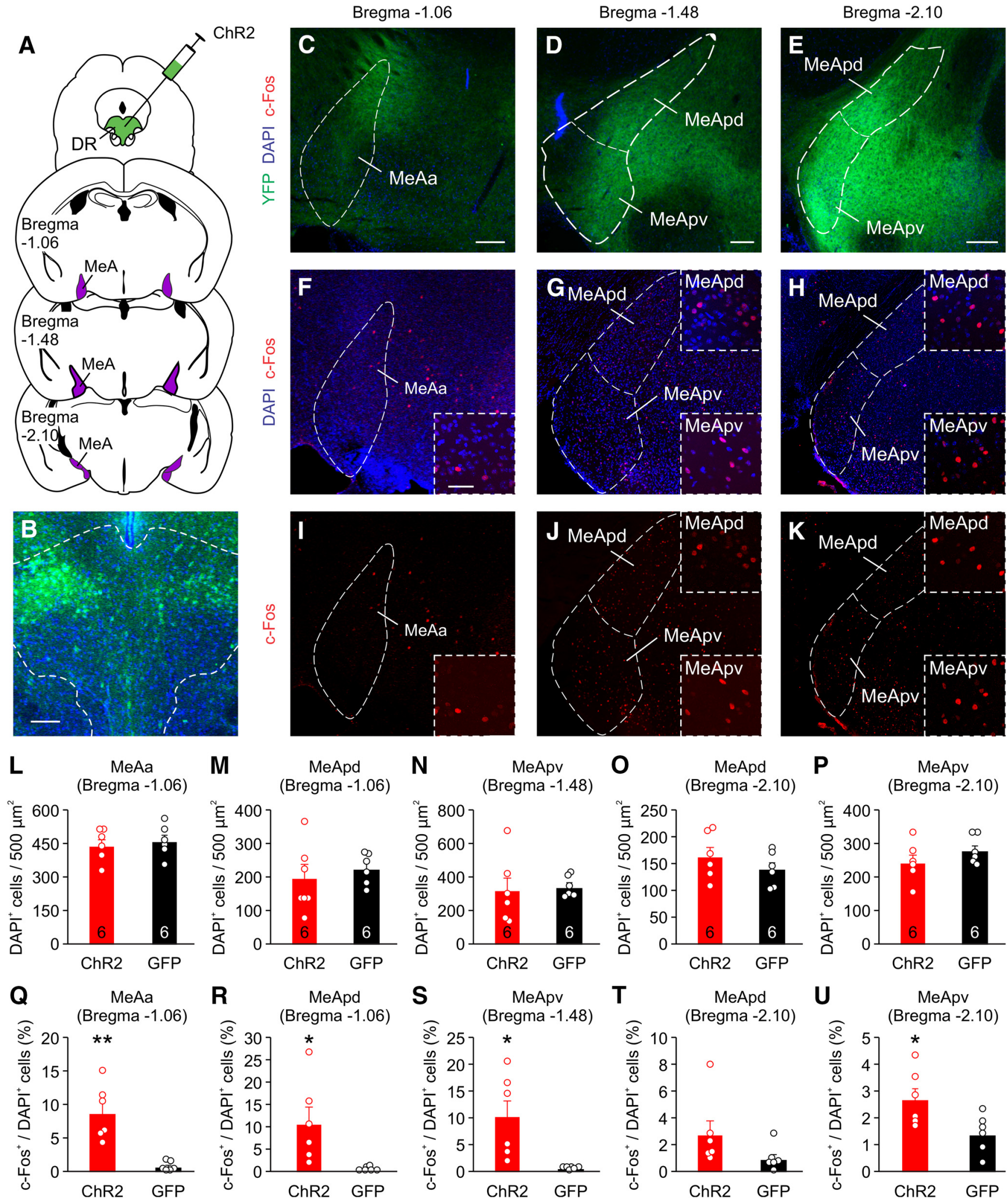

Figure 4. DR neurons project to and activate the MeA. $A-E$, Schematic drawing of ChR2-EYPF injections into the DR and representative images of ChR2 expression in DR neurons $(\boldsymbol{B})$ and axons at the MeA $(\boldsymbol{C}-\boldsymbol{E})$ three weeks later. $\boldsymbol{F}-\boldsymbol{K}, \mathrm{C}-$ Fos labeling of mice photostimulated at the DR-MeA. $\boldsymbol{L}-\boldsymbol{U}$, Quantification of total number of cells $(\boldsymbol{L}-\boldsymbol{M})$ and percentage $(\mathbf{Q}-\boldsymbol{U})$ of $^{\mathrm{C}-\mathrm{Fos}^{+}}$ cells in the MeA (MeAa, anterior MeA; MeApd, posteriordorsal MeA; MeApv, posteriorventral MeA) for $\boldsymbol{D}-\boldsymbol{K}$. Only cells within the MeA were counted. One slice was quantified per area per animal. Animal number is indicated in bars of bar graphs. Scale 
continued

bars: $200 \mu \mathrm{m}(\boldsymbol{A}) ; 200 \mu \mathrm{m}$ (low-magnification images of $\boldsymbol{B}-\boldsymbol{D}$, low-magnification images of $\boldsymbol{F}-\boldsymbol{K}$ ); $50 \mu \mathrm{m}$ (high-magnification images of $\boldsymbol{F}-\boldsymbol{K})$. Data are presented as mean \pm SEM; $* p<0.05, * * p<0.01$. Statistics can be found in Table 2 .

$H, 6 E-H)$. While $561 \mathrm{~nm}$ light had no effect on attack behavior when applied to the MeA, it shortened attack time when applied to the MeOC (Figs. 5/-L, 6/-L). The ChR2/ ArchT and GFP control groups had comparable attack behavior before light stimulation (Figs. $5 F-H, J-L, 6 F-H, J-L$ ). These results suggest that the input from DR CaMKII $\alpha^{+}$ neurons to the MeOC is required for attack to continue. Furthermore, stimulating the DR axons at the MeOC during an attack with $473 \mathrm{~nm}$ light pulses significantly increased attack duration, again with no differences in baseline attacks or in attack behavior during the pre-light stimulation period (Fig. 7A-H). These results indicate that the DR-MeOC pathway can prolong an already occurring attack.

Stimulation of the MeA has been shown to suppress aggression (Rodgers, 1977; Puciłowski et al., 1985; Hong et al., 2014). To assess whether stimulation of the input from DR CaMKIla1 neurons to the MeA may inhibit ongoing attack, we stimulated the MeA of mice injected with AAV
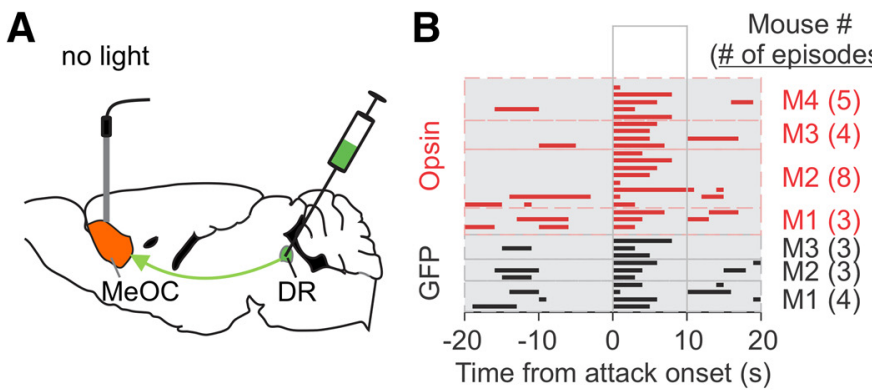

E

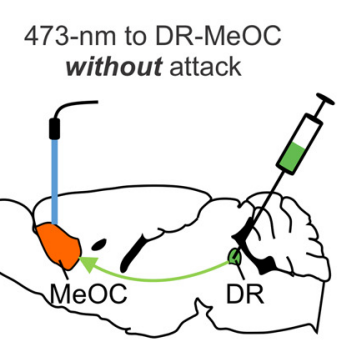

$\mathbf{F}$

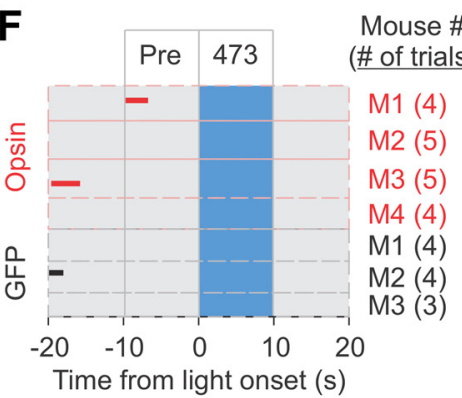

I

561-nm to DR-MeOC during attack

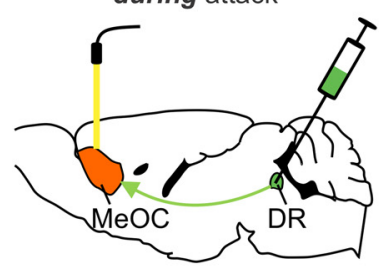

$\mathbf{J}$

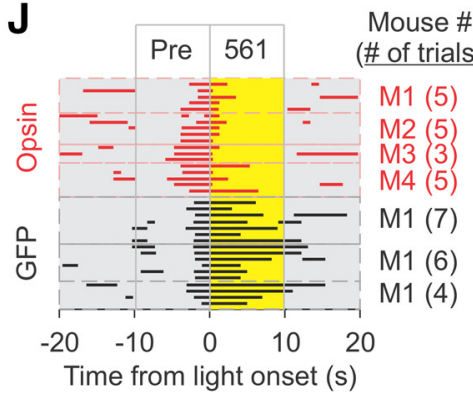

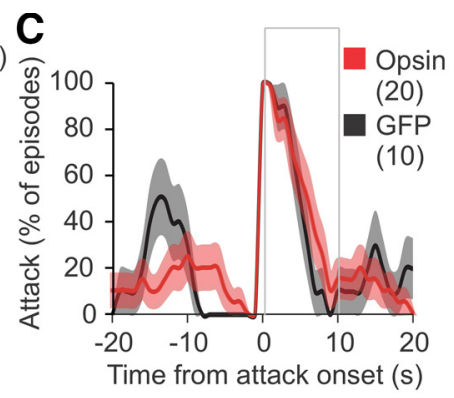
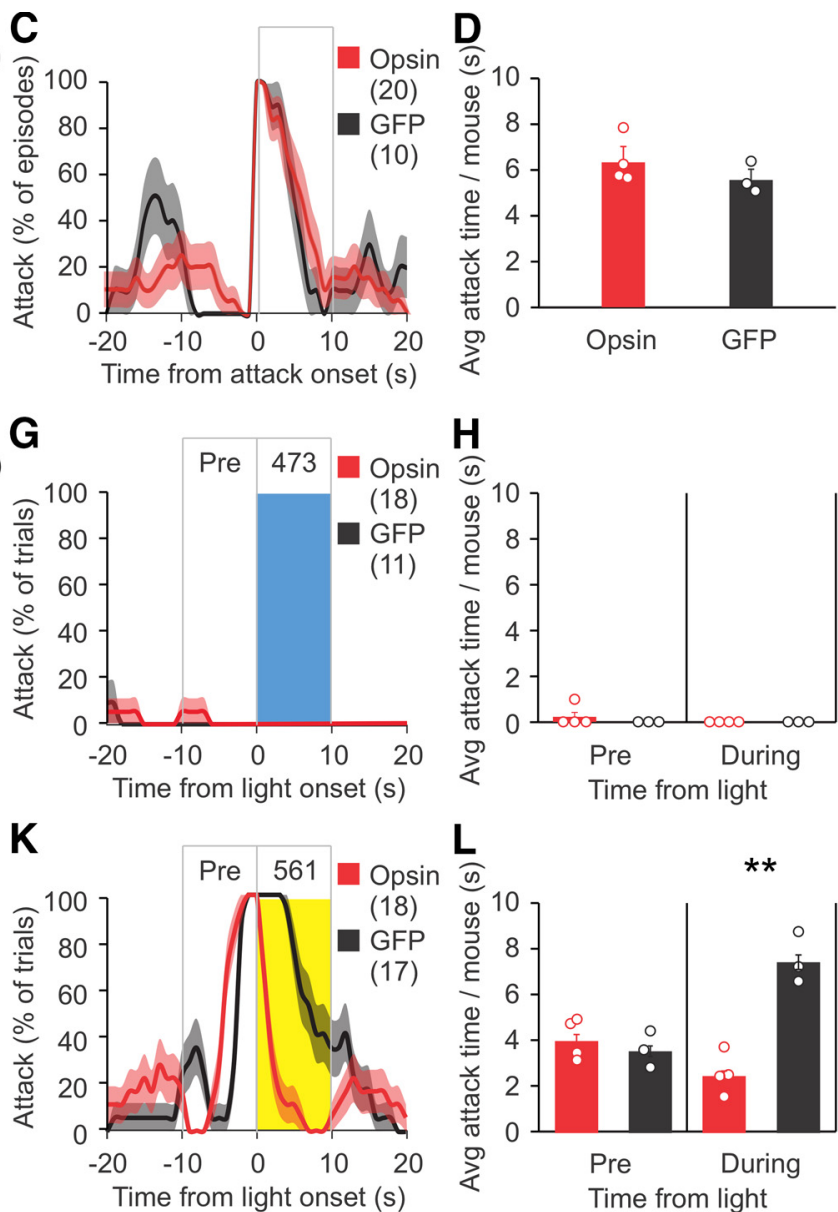

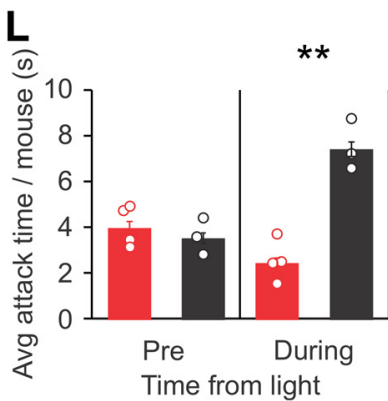

Figure 5. Inhibition of CaMKIl $\alpha^{+}$DR input to the MeOC shortens attack. $\boldsymbol{A}, \boldsymbol{E}$, I, Schematic drawing of viral injection (AAV expressing ChR2 and ArchT or GFP control virus), placement of optic fiber, and stimulation procedure. Opsin expressing mice in $\boldsymbol{A}-\boldsymbol{D}$ and opsin stimulated mice in $\boldsymbol{E}-\boldsymbol{L}$ were injected with ChR2 virus and ArchT virus. The same mice were stimulated with 473 or $561 \mathrm{~nm}$ light on separate days. $\boldsymbol{B}$, Raster plots of attack events during each interaction episode (rows in the raster plot, defined as the period from $20 \mathrm{~s}$ before to $20 \mathrm{~s}$ after the onset of a spontaneous attack) for each mouse. All attack events during the testing period are shown. $\boldsymbol{C}, \%$ of episodes (rows) in which mice attacked at each time point in $\boldsymbol{B}$; red and dark lines indicate the mean, pink and gray areas indicate SEM. D, Quantification of average attack time per mouse during the $10 \mathrm{~s}$ after the onset of a spontaneous attack, as represented in the boxed area in $\boldsymbol{C}$. $\boldsymbol{F}$, Raster plots of trials (rows) of mice photostimulated with $473 \mathrm{~nm}$ light at the DR-MeOC when the mouse was not attacking. $\mathbf{G}, \%$ of trials in which mice attacked at each time point in $\boldsymbol{F}$; red and dark lines indicate the mean, pink and gray areas indicate SEM. $\boldsymbol{H}$, Quantification of attack time per mouse before and during light stimulation for $\boldsymbol{F}$. $\boldsymbol{J}$, Raster plots of trials (rows) of mice photostimulated with $561 \mathrm{~nm}$ light at the DR-MeOC during an attack. $\boldsymbol{K}$, \% of trials in which mice attacked at each time point in $\mathbf{J}$; red and dark lines indicate the mean, pink and gray areas indicate SEM. $\mathbf{L}$, Quantification of attack time per mouse before and during light stimulation for $\boldsymbol{J}$. Data are presented as mean $\pm \mathrm{SEM} ; * p<0.01$. Statistics can be found in Table 2. 
A

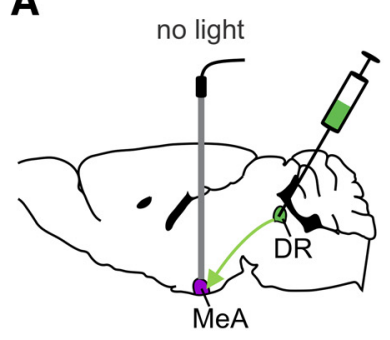

E

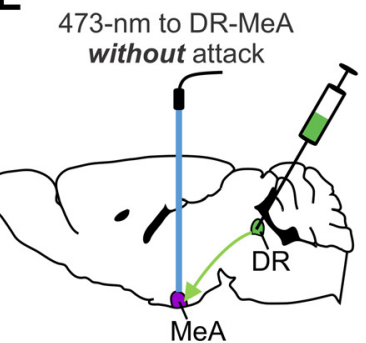

I

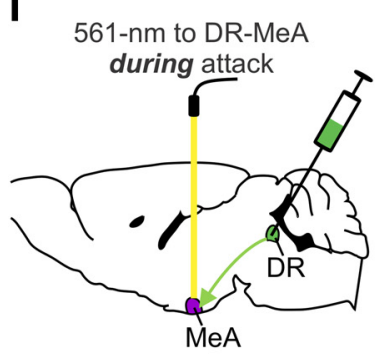

B

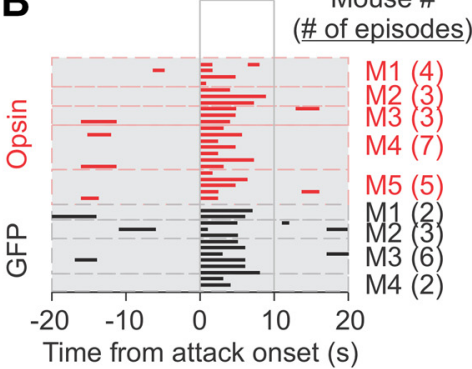

$\mathbf{F}$

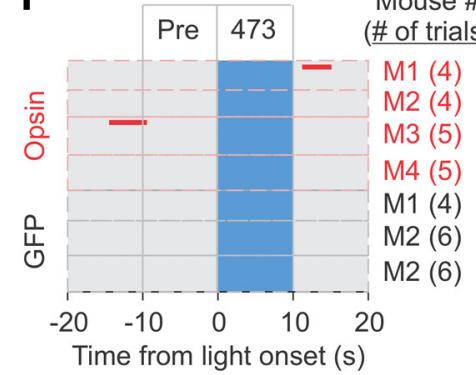

J

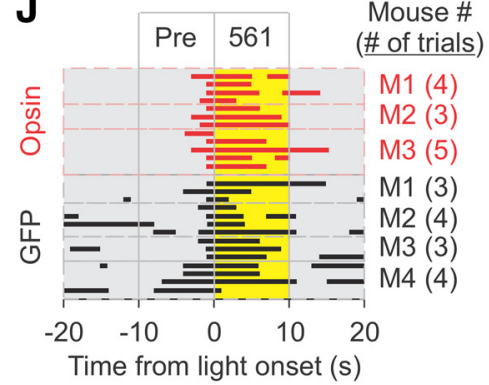

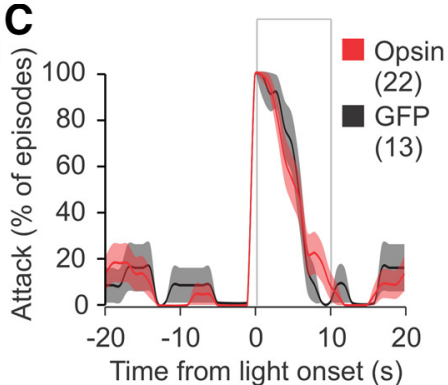

G
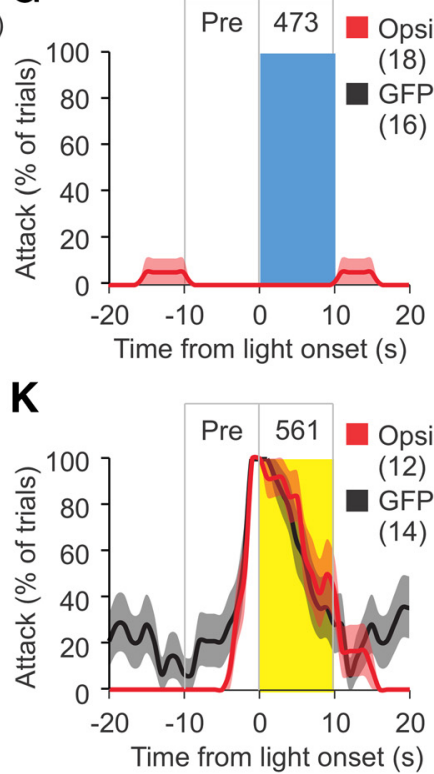

D

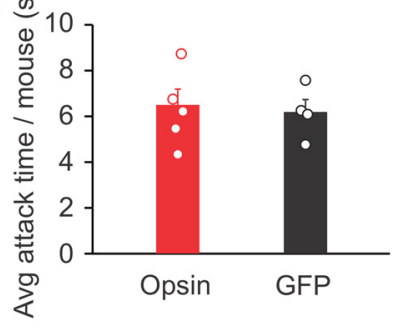

H

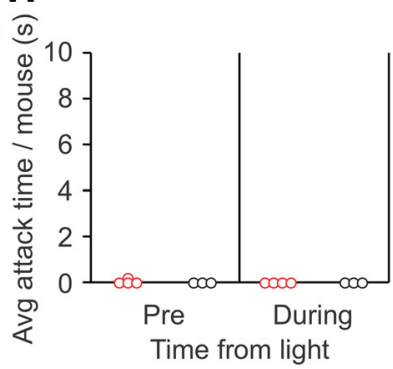

L

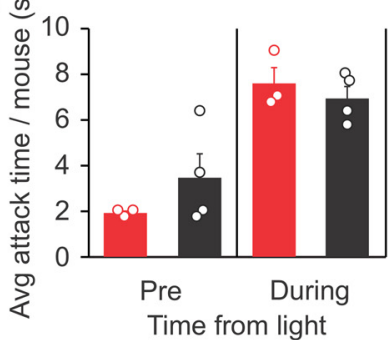

Figure 6. Effects on attack of CaMKII $\alpha^{+}$DR input to the MeA. $\boldsymbol{A}, \boldsymbol{E}, \boldsymbol{I}$, Schematic drawing of viral injection (AAV expressing ChR2 and ArchT or GFP control virus), placement of optic fiber, and stimulation procedure. Opsin expressing mice in $\boldsymbol{A}-\boldsymbol{D}$ and opsin stimulated mice in $\boldsymbol{E}-\boldsymbol{L}$ were injected with ChR2 virus and ArchT virus. The same mice were stimulated with $473 \mathrm{or} 561 \mathrm{~nm}$ light on separate days. $\boldsymbol{B}$, Raster plots of attack events during each interaction episode (rows in the raster plot, defined as the period from $20 \mathrm{~s}$ before to $20 \mathrm{~s}$ after the onset of a spontaneous attack) for each mouse. All attack events during the testing period are shown. $\boldsymbol{C}, \%$ of episodes (rows) in which mice attacked at each time point in $\boldsymbol{B}$; red and dark lines indicate the mean, pink and gray areas indicate SEM. D, Quantification of average attack time per mouse for the $10 \mathrm{~s}$ after the onset of a spontaneous attack, as represented in the boxed area in $\boldsymbol{C}$. $\boldsymbol{F}$, Raster plots of trials (rows) of mice photostimulated with $473 \mathrm{~nm}$ light at the DR-MeA when the mouse was not attacking. $\mathbf{G}, \%$ of trials in which mice attacked at each time point in $\boldsymbol{F}$; red and dark lines indicate the mean, pink and gray areas indicate SEM. $\boldsymbol{H}$, Quantification of attack time per mouse before and during light stimulation for $\boldsymbol{F}$. $\boldsymbol{J}$, Raster plots of trials (rows) of mice photostimulated with $561 \mathrm{~nm}$ light at the DR-MeA during an attack. $\boldsymbol{K}$, \% of trials in which mice attacked at each time point in J; red and dark lines indicate the mean, pink and gray areas indicate SEM. $\boldsymbol{L}$, Quantification of attack time per mouse before and during light stimulation for $\boldsymbol{J}$. Data are presented as mean \pm SEM. Statistics can be found in Table 2 .

ChR2 into the DR at the onset of an attack (Fig. $7 M) ; 473 \mathrm{~nm}$ photostimulation of the MeA significantly shortened the duration of an attack during illumination. Baseline and prestimulation attack behaviors were comparable in ChR2 and GFP control mice (Fig. 7I-P). These results suggest that the DR-MeA pathway facilitates the termination of attack.

Taken together, these findings indicate that the projections from the CaMKIl $\alpha^{+}$DR neurons to the $\mathrm{MeOC}$ and MeA have opposite effects on attack behavior, with the DR-MeOC inputs sustaining attack while the DR-MeA inputs shorten attack.

\section{Discussion}

The DR modulates attack behavior during aggressive encounters in rodents (Chen et al., 1994; Takahashi et al.,
2010, 2015; da Veiga et al., 2011; Adachi et al., 2017; Balázsfi et al., 2018; Muroi and Ishii, 2019). The DR contains a heterogenous population of neurons that project to various brain regions to control social behavior and emotion (Challis et al., 2013; Qi et al., 2014; Matthews et al., 2016; Ren et al., 2018; Huang et al., 2019). However, the role of specific DR projections in aggressive behavior is incompletely understood. Here, we show that the DR$\mathrm{MeOC}$ and DR-MeA pathways control attack duration in opposite directions.

The $\mathrm{MeOC}$ and $\mathrm{MeA}$ are subregions densely innervated areas by the DR (Cádiz-Moretti et al., 2016; Murphy and Deutch, 2018; Ren et al., 2018) and are key nodes in the processing of social interaction including aggression (Blair, 2004; Siever, 2008; Rosell et al., 2010; Hong et al., 
A

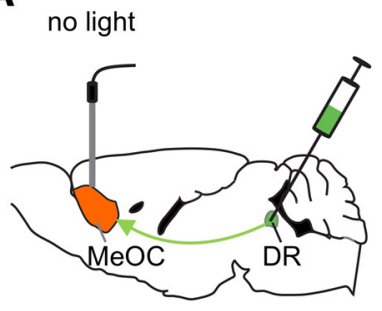

E $\quad 473-n m$ to DR-MeOC during attack

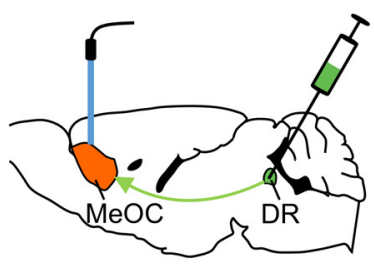

B

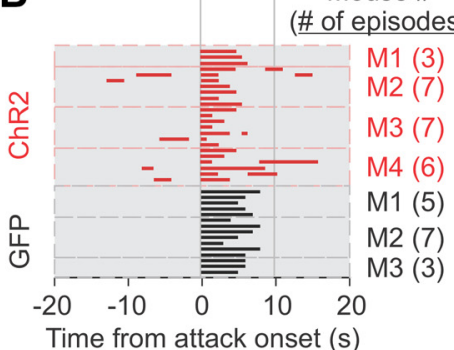

$\mathbf{F}$

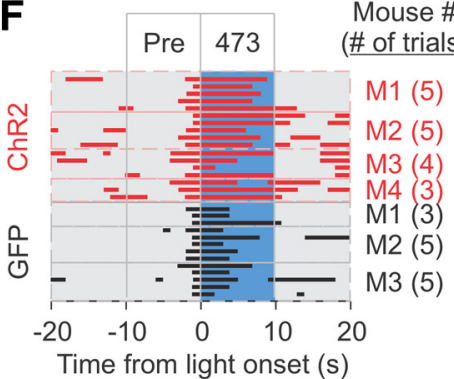

J

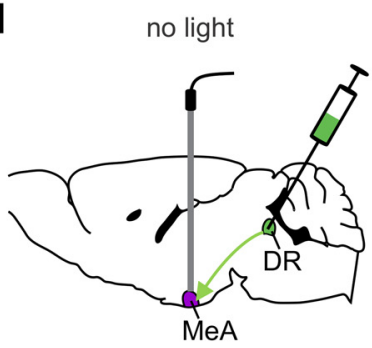

Mouse \#

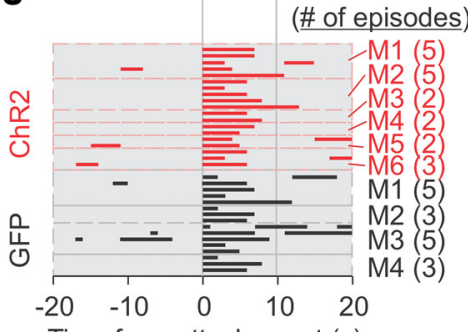

Time from attack onset (s)

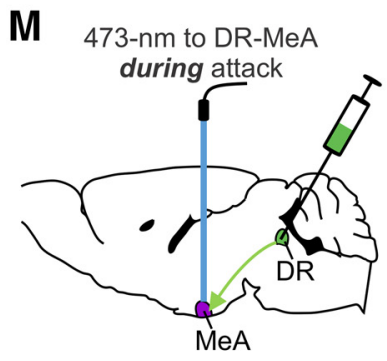

N

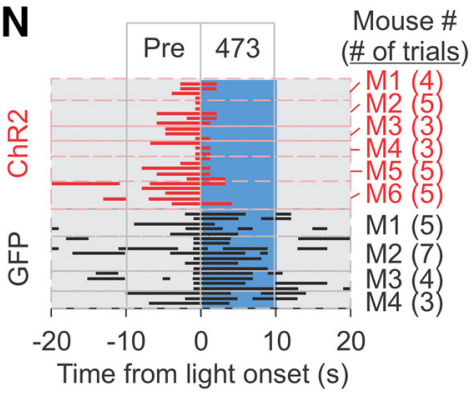

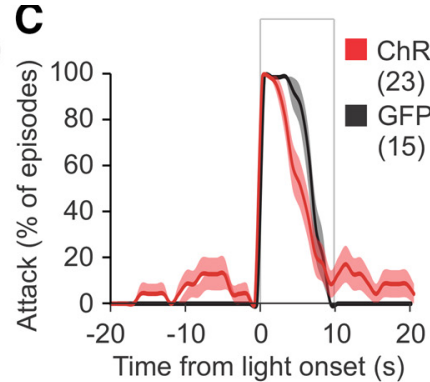
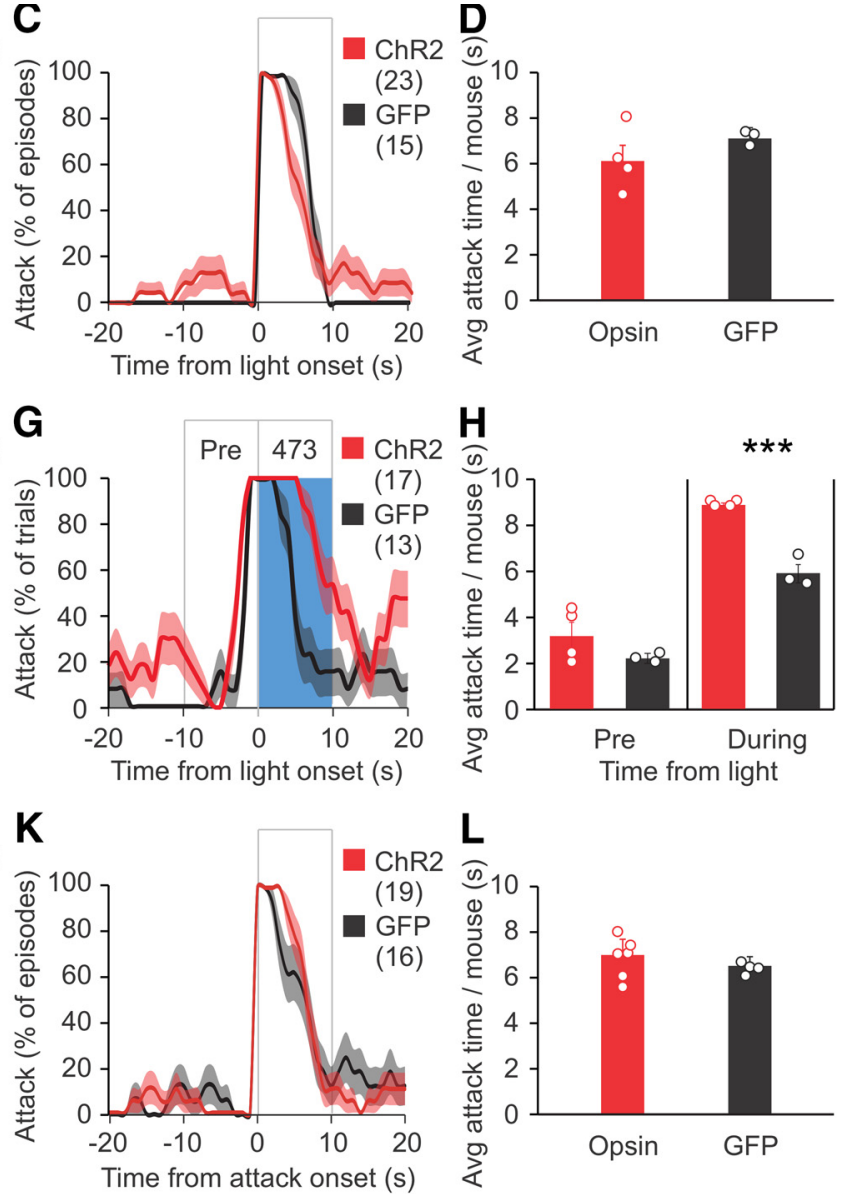

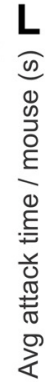

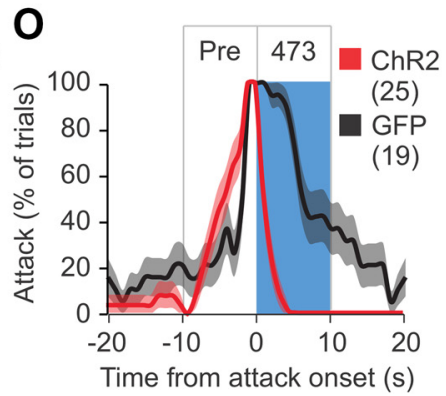

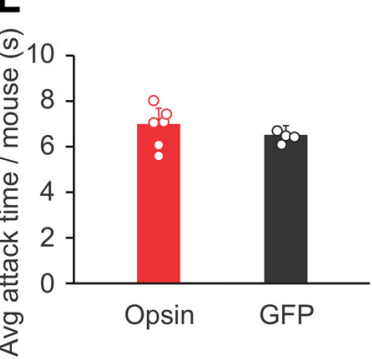

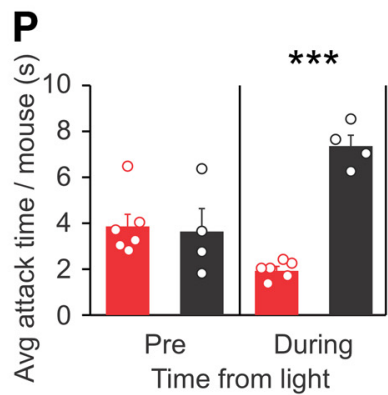

Figure 7. Activation of the DR-MeOC prolongs attack and activation of the DR-MeA shortens attack. Mice were injected with ChR2 virus or GFP virus into the DR and optical fibers were placed into the MeOC $(\boldsymbol{A}, \boldsymbol{E})$ or the $\mathrm{MeA}(\boldsymbol{I}, \boldsymbol{M})$. RI tests were performed eight weeks later. Separate groups of mice were used for $\boldsymbol{A}-\boldsymbol{H}$ and $\boldsymbol{I} \boldsymbol{P}$. $\boldsymbol{B}$, Raster plots of attack events during each interaction episode (rows in the raster plot, defined as the period from $20 \mathrm{~s}$ before to $20 \mathrm{~s}$ after the onset of a spontaneous attack) for each mouse. All attack events during the testing period are shown. $\boldsymbol{C}, \%$ of episodes (rows) in which mice attacked at each time point in $\boldsymbol{B}$; red and dark lines indicate the mean, pink and gray areas indicate SEM. $\boldsymbol{D}$, Quantification of average attack time per mouse for the $10 \mathrm{~s}$ after the onset of a spontaneous attack, as represented in the boxed area in $\boldsymbol{C}$. $\boldsymbol{F}$, Raster plots of trials (rows) of mice photostimulated with $473 \mathrm{~nm}$ light at the DR-MeOC during an attack. G, \% of trials in which mice attacked at each time point in F; red and dark lines indicate the mean, pink and gray areas indicate SEM. $\boldsymbol{H}$, Quantification of attack time per mouse before and during light stimulation for $\boldsymbol{F}$. $\boldsymbol{J}$, Raster plots of attack events during each interaction episode (rows in the raster plot, defined as the period from $20 \mathrm{~s}$ before to $20 \mathrm{~s}$ after the onset of a spontaneous attack) for each mouse. All attack events during the testing period are shown. $\boldsymbol{K}$, \% of episodes (rows) in which mice attacked at each time point in $\mathbf{J}$; red and dark lines indicate the mean, pink and gray areas indicate SEM. $L$, Quantification of average attack time per mouse for the $10 \mathrm{~s}$ after the onset of a spontaneous attack, as represented in the boxed area in $\boldsymbol{J} . \boldsymbol{N}$, Raster plots of trials (rows) of mice photostimulated with $473 \mathrm{~nm}$ light at the DR-MeA during an attack. $\mathbf{O}$, \% of trials in which mice attacked at each time point in $\mathbf{N}$; red and dark lines indicate the mean, pink and gray areas indicate SEM. $\boldsymbol{P}$, Quantification of attack time per mouse before and during light stimulation for $\boldsymbol{N}$. Data are presented as mean \pm SEM; $* * * p<0.001$. Statistics can be found in Table 2 . 
2014; Rosell and Siever, 2015; Unger et al., 2015; Buades-Rotger et al., 2017; Haller, 2018). Activity within the OFC is negatively correlated with aggression and chronic inactivation or lesioning in this area heightens aggression in mice and humans (Anderson et al., 1999; Blair, 2004; Siever, 2008; Rosell et al., 2010; Beyer et al., 2015; Rosell and Siever, 2015; Kuniishi et al., 2016). The role of the MeA in aggression is better characterized. Within the MeA, activation of GABAergic neurons in the MeApd promote attack, while activation of glutamatergic neurons suppress it (Hong et al., 2014; Padilla et al., 2016). Stimulation of dopamine $\mathrm{D} 1$ receptor (D1R)-expressing neurons within the MeApv projecting to the bed nucleus of the stria terminalis increases aggression, while stimulation of those projecting to the ventromedial hypothalamus decreases aggression (Miller et al., 2019). Potentiation of synapses between the MeApv and the ventromedial hypothalamus and bed nucleus of the stria terminalis underlies aggression priming and heightened aggression induced by traumatic stress (Nordman et al., 2020a,b). Notably, dysfunction within the OFC and MeA is associated with excessive and impulsive aggression in mice and humans (Grafman et al., 1996; Blair, 2004; New et al., 2004; Shalom et al., 2004; Coccaro et al., 2007; Mpakopoulou et al., 2008; BuadesRotger et al., 2017; Herpertz et al., 2017). In this study, we chose to stimulate the axons of the $\mathrm{CaMKIl} \alpha^{+}$DR neurons at the MeOC and MeA to discriminate the effects of different pathways on attack behavior. We show that optogenetic silencing of $\mathrm{CaMKII} \alpha^{+}$neurons in the DR and their projections to the MeOC reduces the duration of an attack while optogenetic activation of the DR-MeOC prolongs it. Conversely, activation of the DR-MeA projections reduces attack duration. These results raise the possibility that distinct groups of $\mathrm{CaMKII} \alpha^{+}$DR neurons project to the MeOC and MeA. It is interesting that stimulating the DR-MeOC pathway mimics the effect of stimulating the DR on aggression, suggesting that the DR-MeOC pathway predominates over the DR-MeA pathway. It is noted that the MeA receives direct inputs from the OFC (Siever, 2008; Márquez et al., 2013; Cádiz-Moretti et al., 2016), leaving open the possibility that the DR-MeA pathway is suppressed by OFC input when the DR-MeOC pathway is activated.

The CaMKIl $\alpha$ promoter has been extensively used to drive gene expression in excitatory neurons, though it is also active in a small number of inhibitory neurons in the cortex (Scheyltjens et al., 2015; Watakabe et al., 2015). In addition, many glutamatergic cells of the DR co-release serotonin (Liu et al., 2014; Ren et al., 2018; Huang et al., 2019). Thus, one limitation of our study is that our AAV with the CaMKII $\alpha$ promoter may transduce non-excitatory neurons in the DR. It is noted that in a previous study stimulation of DR neurons that were transduced with AAV expressing ChR2 under the pan neuronal promoter synapsin lead to a decrease in aggression and an increase in 5-HT and GABA release at the PFC (Balázsfi et al., 2018). These synapsin promoter targeted neurons likely overlap with the CaMKII $\alpha^{+}$promoter targeted neurons in this study. This raises an intriguing possibility that the $\mathrm{CaMKII} \alpha^{+}$DR neurons may release neurotransmitters other than glutamate to regulate aggressive behavior. Our finding that the CaMKII $\alpha^{+} \mathrm{DR}$ neurons do not overlap with the serotonergic cell marker $\mathrm{TpH} 2$ would suggest that the $\mathrm{CaMKII} \alpha^{+}$cells are non-serotonergic (Figs. 1G-I, 2E-G). The release of other neurotransmitters, however, cannot be ruled out.

The three main MeA subregions, MeAa, MeApd, and MeApv, are all involved in aggressive behavior (KollackWalker and Newman, 1995; Lin et al., 2011; Hong et al., 2014; Miller et al., 2019; Nordman et al., 2020b). While we observed that photostimulation of the DR can activate all three subregions, since the MeApd and MeApv have different effects on aggression (Kollack-Walker and Newman, 1995; Lin et al., 2011; Hong et al., 2014; Miller et al., 2019; Nordman et al., 2020a), it is worth considering that the DR may be shortening an attack through a specific subregion of the MeA. The photostimulation protocol used in this study does not allow for discrimination of these subregions because of their anatomic clustering.

Aggression is an adaptive behavior with the intention of preserving resources or protecting oneself from harm. Excessive aggression, however, is energetically unfavorable (Maynard Smith and Price, 1973; Haller, 1995; Miczek et al., 2013). In mice, prolonged attack is an indicator of excessive aggression (Miczek et al., 2013). The neural circuits that underlie prolonged aggression are poorly defined. Our study demonstrates that while neither the DRMeOC or DR-MeA pathway can initiate an attack, both pathways regulate the duration of an already occurring attack. These findings suggest an intriguing possibility that dysfunction within these DR pathways may play a role in excessive aggression.

\section{References}

Adachi M, Autry AE, Mahgoub M, Suzuki K, Monteggia LM (2017) TrkB signaling in dorsal raphe nucleus is essential for antidepressant efficacy and normal aggression behavior. Neuropsychopharmacology 42:886-894.

Anderson SW, Bechara A, Damasio H, Tranel D, Damasio AR (1999) Impairment of social and moral behavior related to early damage in human prefrontal cortex. Nat Neurosci 2:1032-1037.

Balázsfi D, Zelena D, Demeter K, Miskolczi C, Varga ZK, Nagyváradi Á, Nyíri G, Cserép C, Baranyi M, Sperlágh B, Haller J (2018) Differential roles of the two raphe nuclei in amiable social behavior and aggression - an optogenetic study. Front Behav Neurosci 12:163.

Benson DL, Isackson PJ, Gall CM, Jones EG (1992) Contrasting patterns in the localization of glutamic-acid decarboxylase and $\mathrm{Ca} 2+/$ calmodulin protein-kinase gene-expression in the rat central-nervous-system. Neuroscience 46:825-849.

Beyer F, Münte TF, Göttlich M, Krämer UM (2015) Orbitofrontal cortex reactivity to angry facial expression in a social interaction correlates with aggressive behavior. Cereb Cortex 25:3057-3063.

Blair RJ (2004) The roles of orbital frontal cortex in the modulation of antisocial behavior. Brain Cogn 55:198-208.

Blanchard RJ, Blanchard DC (1977) Aggressive behavior in the rat. Behav Biol 21:197-224.

Buades-Rotger M, Beyer F, Krämer UM (2017) Avoidant responses to interpersonal provocation are associated with increased amygdala and decreased mentalizing network activity. eNeuro 4.

Cádiz-Moretti B, Otero-García M, Martínez-García F, Lanuza E (2016) Afferent projections to the different medial amygdala 
subdivisions: a retrograde tracing study in the mouse. Brain Struct Funct 221:1033-1065.

Challis C, Boulden J, Veerakumar A, Espallergues J, Vassoler FM, Pierce RC, Beck SG, Berton O (2013) Raphe GABAergic neurons mediate the acquisition of avoidance after social defeat. $J$ Neurosci 33:13978-13988, 13988a.

Chen C, Rainnie DG, Greene RW, Tonegawa S (1994) Abnormal fear response and aggressive behavior in mutant mice deficient for alpha-calcium-calmodulin kinase II. Science 266:291-294.

Clarke HF, Walker SC, Dalley JW, Robbins TW, Roberts AC (2007) Cognitive inflexibility after prefrontal serotonin depletion is behaviorally and neurochemically specific. Cereb Cortex 17:18-27.

Coccaro EF, McCloskey MS, Fitzgerald DA, Phan KL (2007) Amygdala and orbitofrontal reactivity to social threat in individuals with impulsive aggression. Biol Psychiatry 62:168-178.

Commons KG (2009) Locally collateralizing glutamate neurons in the dorsal raphe nucleus responsive to substance $P$ contain vesicular glutamate transporter 3 (VGLUT3). J Chem Neuroanat 38:273281.

da Veiga CP, Miczek KA, Lucion AB, de Almeida RM (2011) Social instigation and aggression in postpartum female rats: role of $5-\mathrm{Ht} 1 \mathrm{~A}$ and $5-\mathrm{Ht} 1 \mathrm{~B}$ receptors in the dorsal raphe nucleus and prefrontal cortex. Psychopharmacology (Berl) 213:475-487.

De Almeida RM, Rosa MM, Santos DM, Saft DM, Benini Q, Miczek KA (2006) 5-HT(1B) receptors, ventral orbitofrontal cortex, and aggressive behavior in mice. Psychopharmacology (Berl) 185:441450.

Golden SA, Heshmati M, Flanigan M, Christoffel DJ, Guise K, Pfau ML, Aleyasin H, Menard C, Zhang H, Hodes GE, Bregman D, Khibnik L, Tai J, Rebusi N, Krawitz B, Chaudhury D, Walsh JJ, Han MH, Shapiro ML, Russo SJ (2016) Basal forebrain projections to the lateral habenula modulate aggression reward. Nature 534:688-692.

Grafman J, Schwab K, Warden D, Pridgen A, Brown HR, Salazar AM (1996) Frontal lobe injuries, violence, and aggression: a report of the Vietnam Head Injury Study. Neurology 46:1231-1238.

Gunaydin LA, Yizhar O, Berndt A, Sohal VS, Deisseroth K, Hegemann P (2010) Ultrafast optogenetic control. Nat Neurosci 13:387-392.

Haller J (1995) Biochemical background for an analysis of cost-benefit interrelations in aggression. Neurosci Biobehav Rev 19:599604.

Haller $\mathrm{J}$ (2018) The role of central and medial amygdala in normal and abnormal aggression: a review of classical approaches. Neurosci Biobehav Rev 85:34-43.

Herpertz SC, Nagy K, Ueltzhöffer K, Schmitt R, Mancke F, Schmahl C, Bertsch K (2017) Brain mechanisms underlying reactive aggression in borderline personality disorder-sex matters. Biol Psychiatry 82:257-266.

Holschbach MA, Vitale EM, Lonstein JS (2018) Serotonin-specific lesions of the dorsal raphe disrupt maternal aggression and caregiving in postpartum rats. Behav Brain Res 348:53-64.

Hong W, Kim DW, Anderson DJ (2014) Antagonistic control of social versus repetitive self-grooming behaviors by separable amygdala neuronal subsets. Cell 158:1348-1361.

Huang KW, Ochandarena NE, Philson AC, Hyun M, Birnbaum JE, Cicconet M, Sabatini BL (2019) Molecular and anatomical organization of the dorsal raphe nucleus. Elife 8 .

Jiao Y, Sun Z, Lee T, Fusco FR, Kimble TD, Meade CA, Cuthbertson S, Reiner A (1999) A simple and sensitive antigen retrieval method for free-floating and slide-mounted tissue sections. J Neurosci Methods 93:149-162.

Jones EG, Huntley GW, Benson DL (1994) Alpha calcium/calmodulin-dependent protein kinase II selectively expressed in a subpopulation of excitatory neurons in monkey sensory-motor cortex: comparison with GAD-67 expression. J Neurosci 14:611-629.

Kollack-Walker S, Newman SW (1995) Mating and agonistic behavior produce different patterns of Fos immunolabeling in the male Syrian hamster brain. Neuroscience 66:721-736.
Koolhaas JM, Coppens CM, de Boer SF, Buwalda B, Meerlo P, Timmermans PJ (2013) The resident-intruder paradigm: a standardized test for aggression, violence and social stress. J Vis Exp. Advance online publication. Retrieved July 4, 2013. doi: 10.3791/ 4367.

Kuniishi H, Ichisaka S, Matsuda S, Futora E, Harada R, Hata Y (2016) Chronic inactivation of the orbitofrontal cortex increases anxietylike behavior and impulsive aggression, but decreases depression-like behavior in rats. Front Behav Neurosci 10:250.

Lin D, Boyle MP, Dollar P, Lee H, Lein ES, Perona P, Anderson DJ (2011) Functional identification of an aggression locus in the mouse hypothalamus. Nature 470:221-226.

Liu XB, Jones EG (1996) Localization of alpha type II calcium calmodulin-dependent protein kinase at glutamatergic but not gamma-aminobutyric acid (GABAergic) synapses in thalamus and cerebral cortex. Proc Natl Acad Sci USA 93:7332-7336.

Liu Z, Zhou J, Li Y, Hu F, Lu Y, Ma M, Feng Q, Zhang JE, Wang D, Zeng J, Bao J, Kim JY, Chen ZF, El Mestikawy S, Luo M (2014) Dorsal raphe neurons signal reward through $5-\mathrm{HT}$ and glutamate. Neuron 81:1360-1374.

Malick JB (1979) The pharmacology of isolation-induced aggressive behavior in mice. Curr Dev Psychopharmacol 5:1-27.

Márquez C, Poirier GL, Cordero MI, Larsen MH, Groner A, Marquis J, Magistretti PJ, Trono D, Sandi C (2013) Peripuberty stress leads to abnormal aggression, altered amygdala and orbitofrontal reactivity and increased prefrontal MAOA gene expression. Transl Psychiatry 3:e216.

Matthews GA, Nieh EH, Vander Weele CM, Halbert SA, Pradhan RV, Yosafat AS, Glober GF, Izadmehr EM, Thomas RE, Lacy GD, Wildes CP, Ungless MA, Tye KM (2016) Dorsal raphe dopamine neurons represent the experience of social isolation. Cell 164:617631.

Mattis J, Tye KM, Ferenczi EA, Ramakrishnan C, O'Shea DJ, Prakash R, Gunaydin LA, Hyun M, Fenno LE, Gradinaru V, Yizhar O, Deisseroth K (2011) Principles for applying optogenetic tools derived from direct comparative analysis of microbial opsins. Nat Methods 9:159-172.

Maynard Smith J, Price G (1973) The logic of animal conflict. Nature 246:15-18.

Miczek KA, de Boer SF, Haller J (2013) Excessive aggression as model of violence: a critical evaluation of current preclinical methods. Psychopharmacology (Berl) 226:445-458.

Miller SM, Marcotulli D, Shen A, Zweifel LS (2019) Divergent medial amygdala projections regulate approach-avoidance conflict behavior. Nat Neurosci 22:565-575.

Mpakopoulou M, Gatos H, Brotis A, Paterakis KN, Fountas KN (2008) Stereotactic amygdalotomy in the management of severe aggressive behavioral disorders. Neurosurg Focus 25:E6.

Muroi Y, Ishii T (2019) Glutamatergic signals in the dorsal raphe nucleus regulate maternal aggression and care in an opposing manner in mice. Neuroscience 400:33-47.

Murphy MJM, Deutch AY (2018) Organization of afferents to the orbitofrontal cortex in the rat. J Comp Neurol 526:1498-1526.

Nelson RJ (2006) Biology of aggression. Oxford: Oxford University Press.

Nelson RJ, Trainor BC (2007) Neural mechanisms of aggression. Nat Rev Neurosci 8:536-546.

New AS, Buchsbaum MS, Hazlett EA, Goodman M, Koenigsberg HW, Lo J, Iskander L, Newmark R, Brand J, O’Flynn K, Siever LJ (2004) Fluoxetine increases relative metabolic rate in prefrontal cortex in impulsive aggression. Psychopharmacology (Berl) 176:451-458.

Nordman JC, Ma X, Gu Q, Potegal M, Li H, Kravitz AV, Li Z (2020a) Potentiation of divergent medial amygdala pathways drives experience-dependent aggression escalation. J Neurosci 40:4858-4880.

Nordman J, Ma X, Li Z (2020b) Traumatic stress induces prolonged aggression increase through synaptic potentiation in the medial amygdala circuits. eNeuro 7 . 
Olivier B (2004) Serotonin and aggression. Ann NY Acad Sci 1036:382-392.

Padilla SL, Qiu J, Soden ME, Sanz E, Nestor CC, Barker FD, Quintana A, Zweifel LS, Rønnekleiv OK, Kelly MJ, Palmiter RD (2016) Agouti-related peptide neural circuits mediate adaptive behaviors in the starved state. Nat Neurosci 19:734-741.

Puciłowski O, Płaz nik A, Kostowski W (1985) Aggressive behavior inhibition by serotonin and quipazine injected into the amygdala in the rat. Behav Neural Biol 43:58-68.

Qi J, Zhang S, Wang HL, Wang H, de Jesus Aceves Buendia J, Hoffman AF, Lupica CR, Seal RP, Morales M (2014) A glutamatergic reward input from the dorsal raphe to ventral tegmental area dopamine neurons. Nat Commun 5:5390.

Ren J, Friedmann D, Xiong J, Liu CD, Ferguson BR, Weerakkody T, DeLoach KE, Ran C, Pun A, Sun Y, Weissbourd B, Neve RL, Huguenard J, Horowitz MA, Luo L (2018) Anatomically defined and functionally distinct dorsal raphe serotonin sub-systems. Cell 175:472-487.e20.

Rodgers RJ (1977) The medial amygdala: serotonergic inhibition of shock-Induced aggression and pain sensitivity in rats. Aggr Behav 3:277-288.

Rosell DR, Siever LJ (2015) The neurobiology of aggression and violence. CNS Spectr 20:254-279.

Rosell DR, Thompson JL, Slifstein M, Xu X, Frankle WG, New AS, Goodman M, Weinstein SR, Laruelle M, Abi-Dargham A, Siever LJ (2010) Increased serotonin 2A receptor availability in the orbitofrontal cortex of physically aggressive personality disordered patients. Biol Psychiatry 67:1154-1162.

Scheyltjens I, Laramée ME, Van den Haute C, Gijsbers R, Debyser Z, Baekelandt V, Vreysen S, Arckens L (2015) Evaluation of the expression pattern of $\mathrm{rAAV} 2 / 1,2 / 5,2 / 7,2 / 8$, and 2/9 serotypes with different promoters in the mouse visual cortex. J Comp Neurol 523:2019-2042.

Shalom G, Gur E, Van de Kar LD, Newman ME (2004) Repeated administration of the 5-HT(1B) receptor antagonist SB-224289 blocks the desensitisation of $5-\mathrm{HT}(1 \mathrm{~B})$ autoreceptors induced by fluoxetine in rat frontal cortex. Naunyn Schmiedebergs Arch Pharmacol 370:84-90.

Siever LJ (2008) Neurobiology of aggression and violence. Am J Psychiatry 165:429-442.

Takahashi A, Miczek KA (2014) Neurogenetics of aggressive behavior: studies in rodents. Curr Top Behav Neurosci 17:3-44.

Takahashi A, Shimamoto A, Boyson CO, DeBold JF, Miczek KA (2010) GABA(B) receptor modulation of serotonin neurons in the dorsal raphé nucleus and escalation of aggression in mice. $J$ Neurosci 30:11771-11780.

Takahashi A, Lee RX, Iwasato T, Itohara S, Arima H, Bettler B, Miczek KA, Koide T (2015) Glutamate input in the dorsal raphe nucleus as a determinant of escalated aggression in male mice. $J$ Neurosci 35:6452-6463.

Unger EK, Burke KJ Jr, Yang CF, Bender KJ, Fuller PM, Shah NM (2015) Medial amygdalar aromatase neurons regulate aggression in both sexes. Cell Rep 10:453-462.

Valzelli $L$ (1985) Animal models of behavioral pathology and violent aggression. Methods Find Exp Clin Pharmacol 7:189-193.

Walletschek H, Raab A (1982) Spontaneous activity of dorsal raphe neurons during defensive and offensive encounters in the treeshrew. Physiol Behav 28:697-705.

Watakabe A, Ohtsuka M, Kinoshita M, Takaji M, Isa K, Mizukami H, Ozawa K, Isa T, Yamamori T (2015) Comparative analyses of adeno-associated viral vector serotypes 1, 2, 5, 8 and 9 in marmoset, mouse and macaque cerebral cortex. Neurosci Res 93:144157.

Wilson MA, Molliver ME (1991) The organization of serotonergic projections to cerebral cortex in primates: regional distribution of axon terminals. Neuroscience 44:537-553.

Zhou J, Jia C, Feng Q, Bao J, Luo M (2015) Prospective coding of dorsal raphe reward signals by the orbitofrontal cortex. J Neurosci 35:2717-2730. 